\title{
Red ACOMAR: Real-time networking activities in the Macaronesian region as a contribution to the Coastal Ocean Observations Panel (COOP)
}

C. Barrera(1) , M.J. Rueda(1), M.D. Gelado(2), R. Moran(1), E. Azevedo(3) and O. Llinás(4)

(1) Oceanography Department. Instituto Canario de Ciencias Marinas (ICCM). Las Palmas. Spain.

(2) Chemistry Department. Universidad de Las Palmas de Gran Canaria (ULPGC). Las Palmas. Spain.

(3) Observatorio do Ambiente dos Açores (OAA). Açores. Portugal.

(4) Plataforma Oceanica de Canarias (PLOCAN). Las Palmas. Spain

OCEANS '09 Biloxi, MS (USA) 29th October 2009

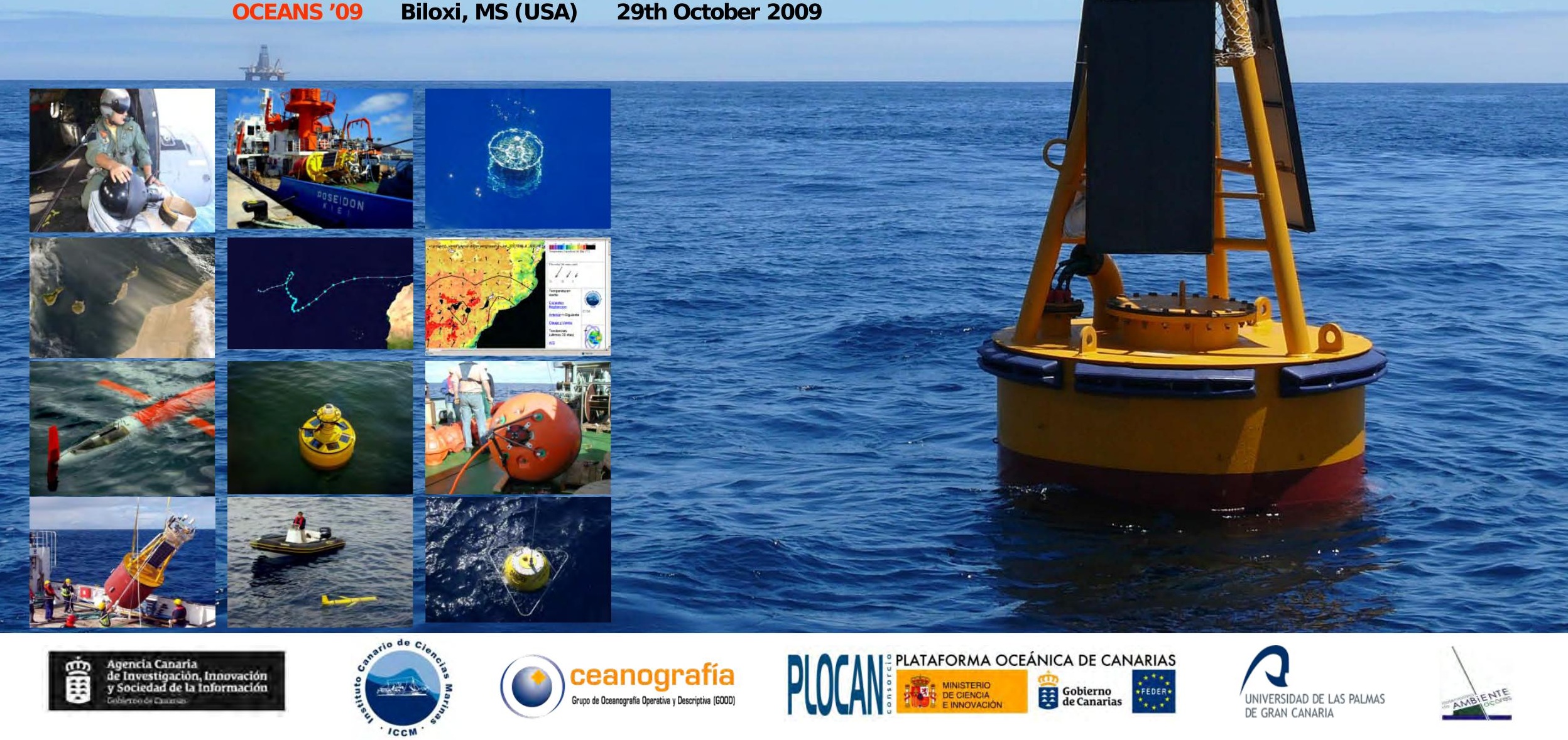




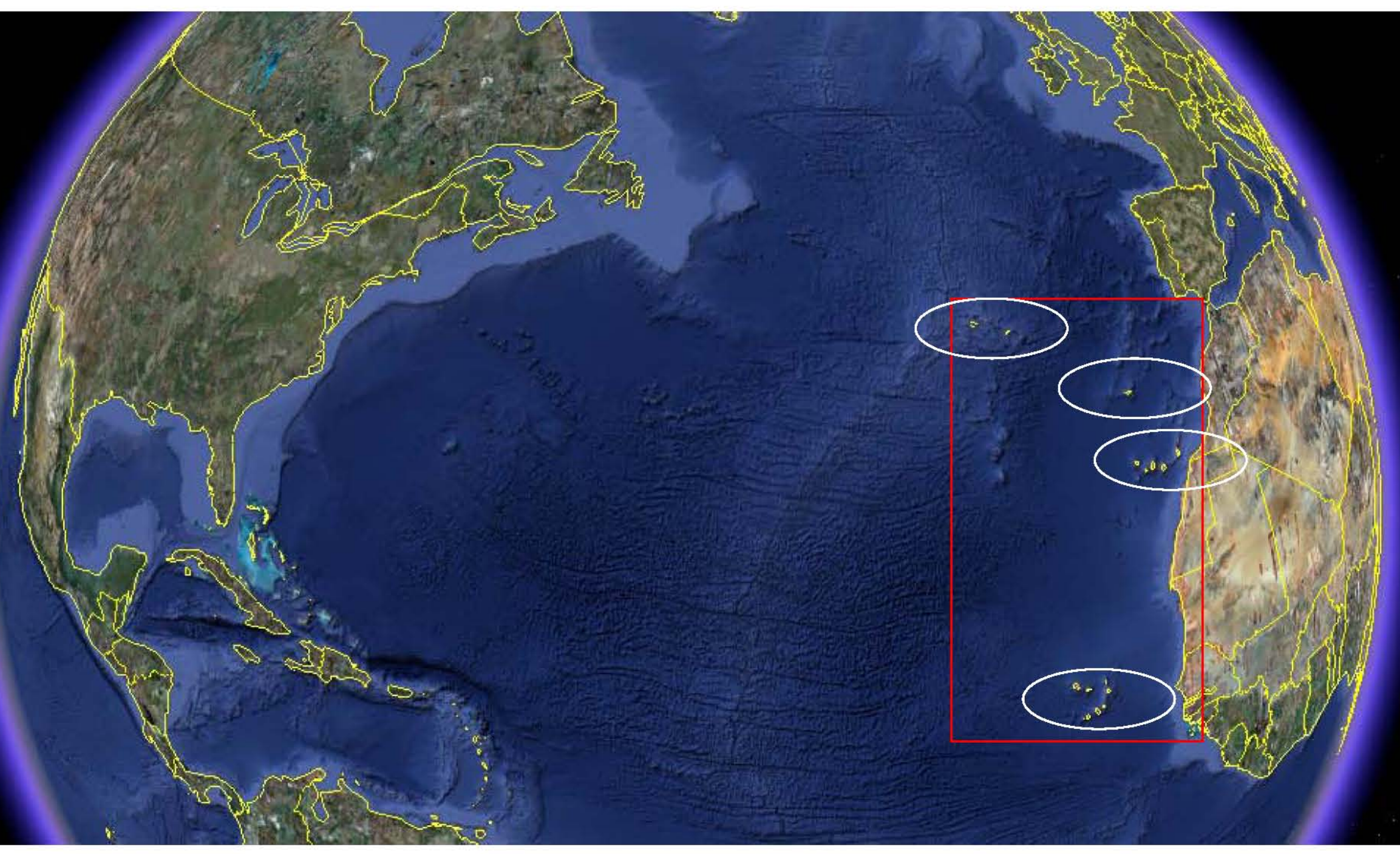

\section{面}




\section{... the GOAL}

NRT Coastal Monitoring Network in the Macaronesian region (1998)

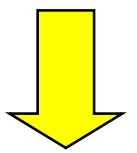

Instituto Canario de Ciencias Marinas (ICCM)- Canarian Government

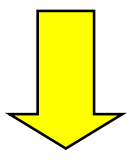

Increase the Marine Environmental Observations Quality and Quantity

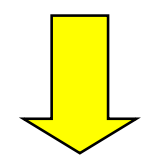

Understand and Forecast

PROCESSES AND PHENOMENA

\section{ENVIRONMENTAL + SOCIO-ECONOMICAL} EFFECTS AND REPERCUSSIONS 


\section{Integrator System}
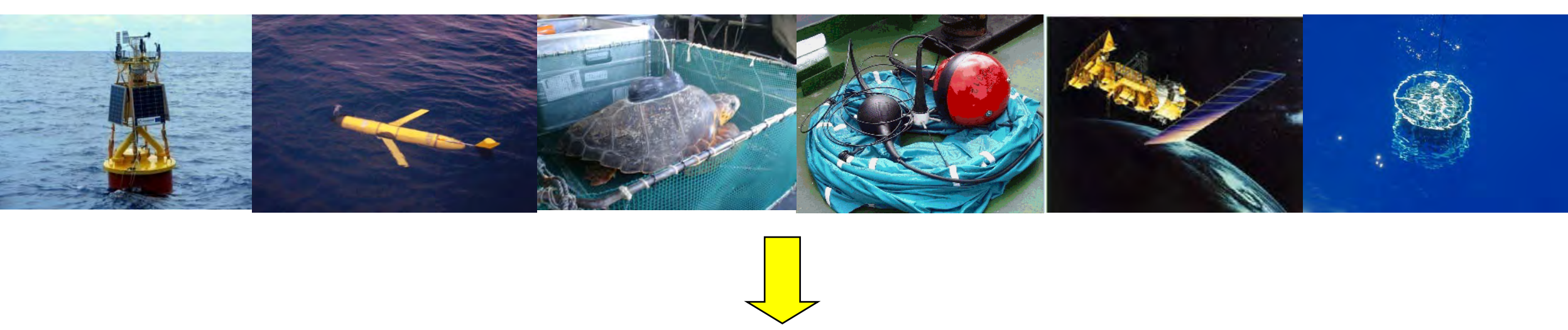

To make compatible and accessible the ALL INFORMATIONS on the Canarian marine enviroment, independently of the data provider institution or monitoring source.

To promote and encourage specific direct /indirect FINAL USERS for each kind of observation and location. 
Real-time monitoring network with final users in the coastal area and directly linked with open-ocean EU-Operational Oceanography projects with ICCM as a partner.

- ANIMATE (FP5)

- MERSEA (FP6)

- ALERMAC (Interreg)

-CLIMARCOST (Interreg)

-AMASS (FP7)

-EuroSITES (FP7)

-PLOCAN

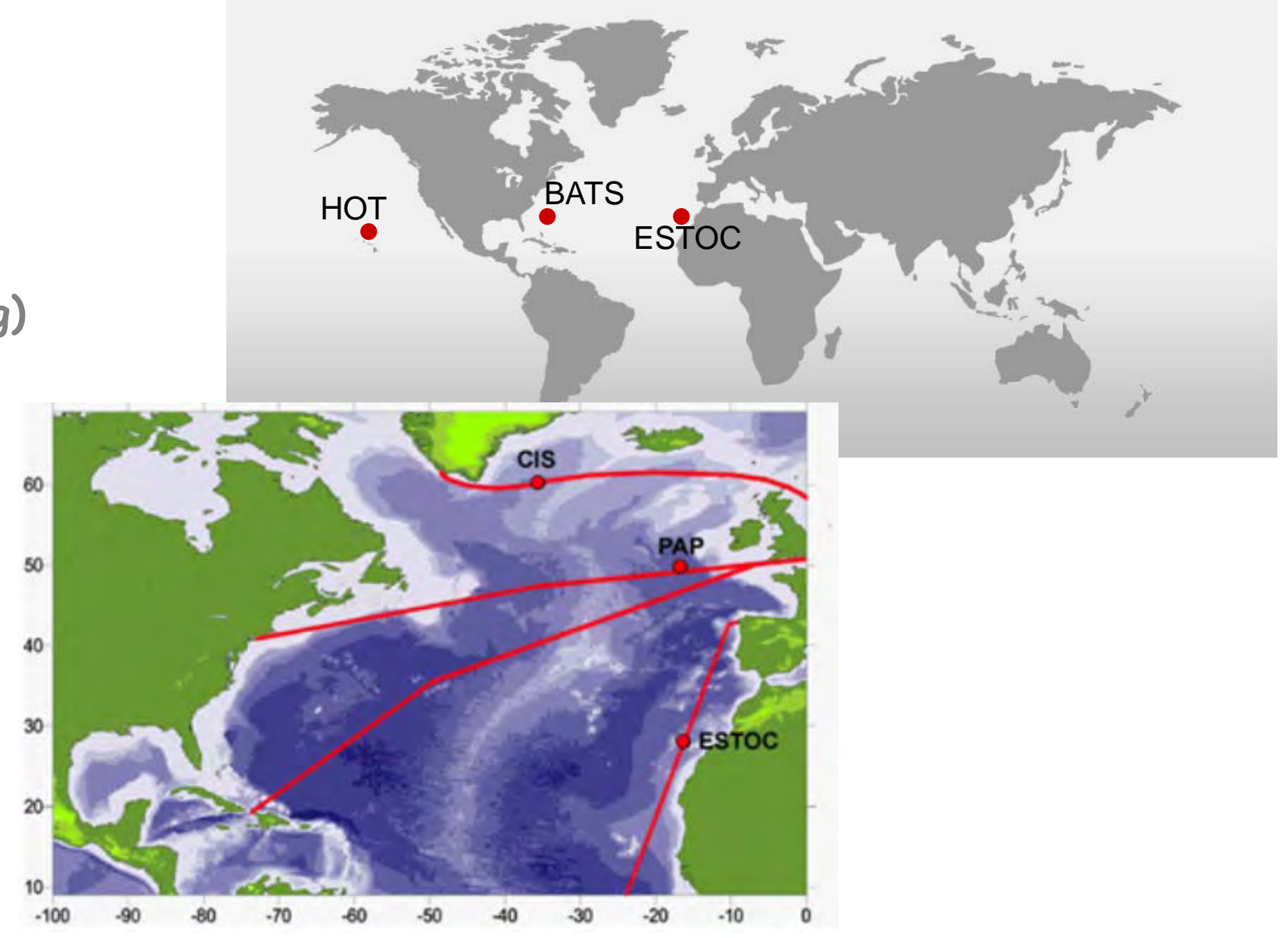




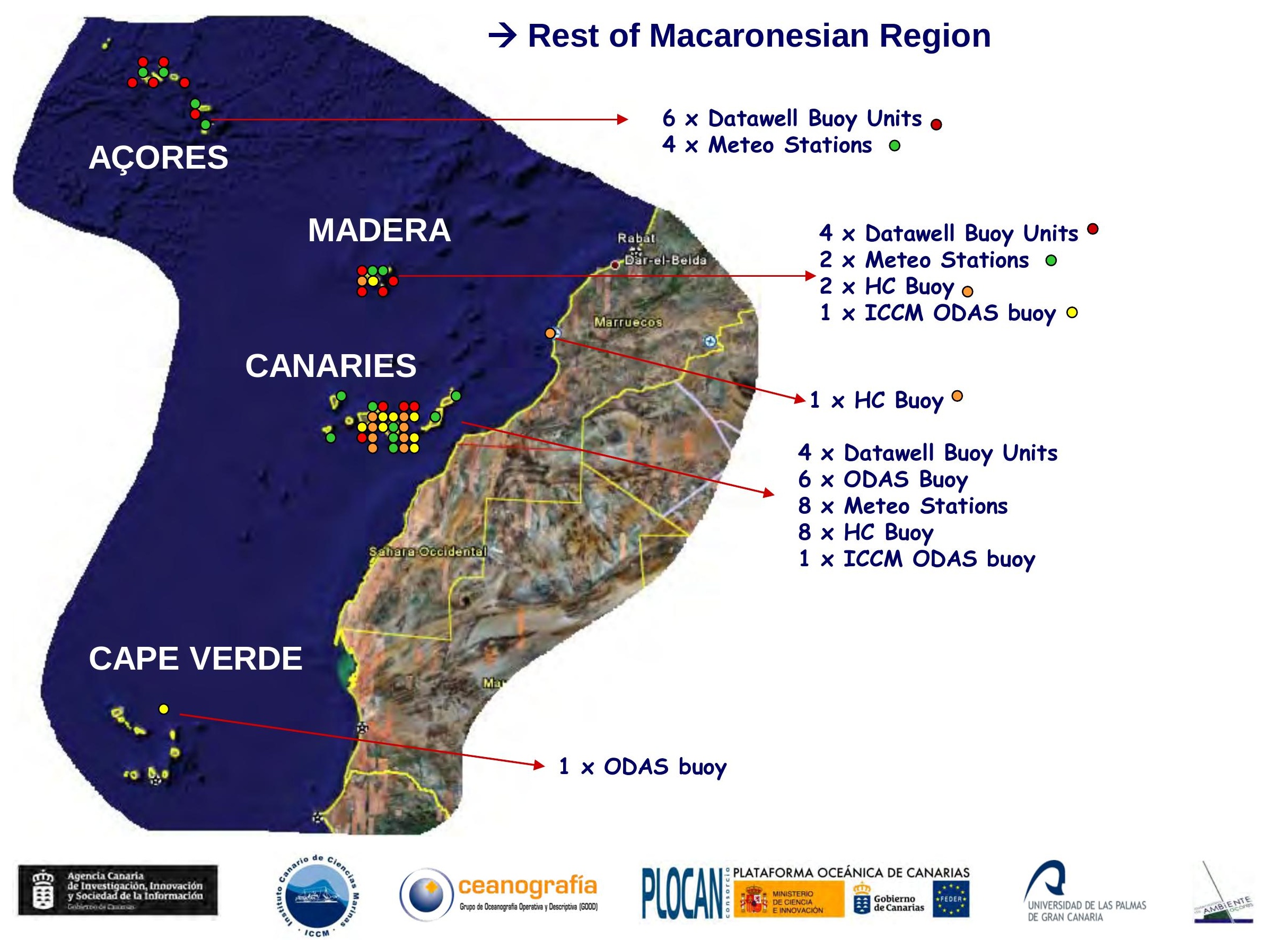


Moored Buoys

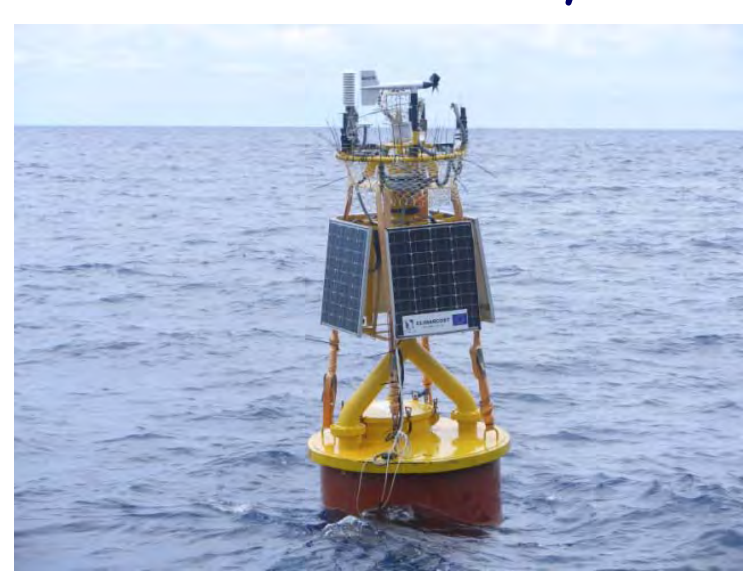

Met Stations

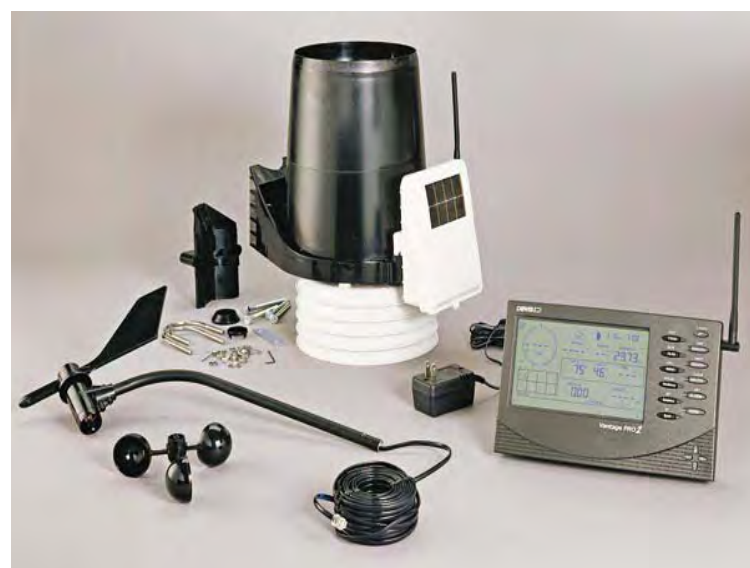

Drifters

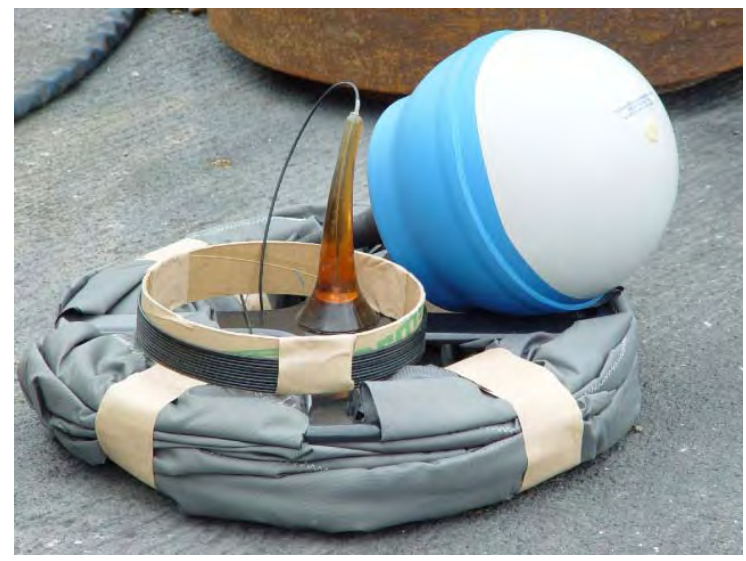

Remote Sensing

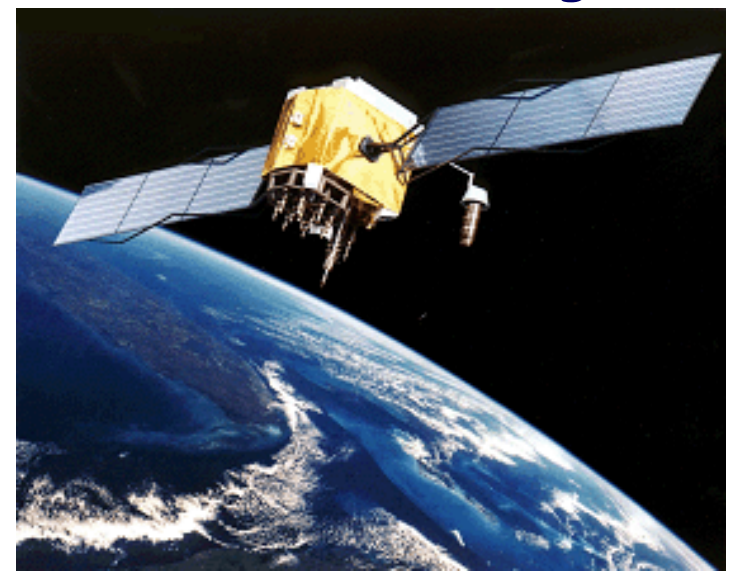

Gliders

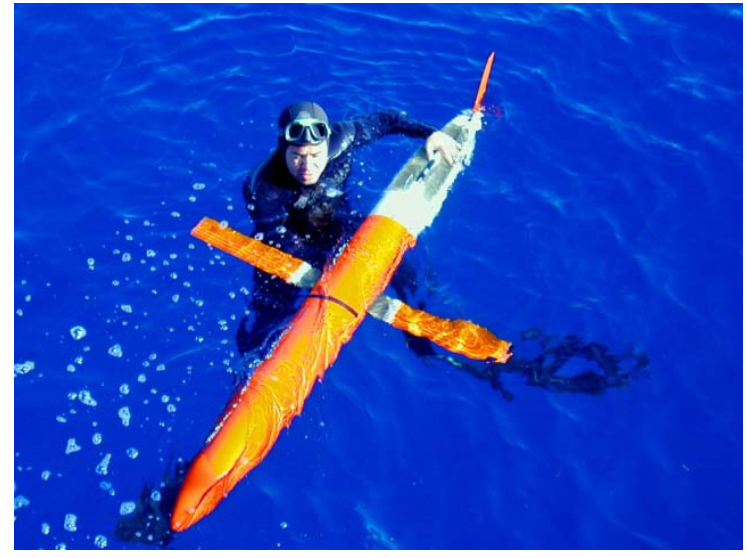

Turtles

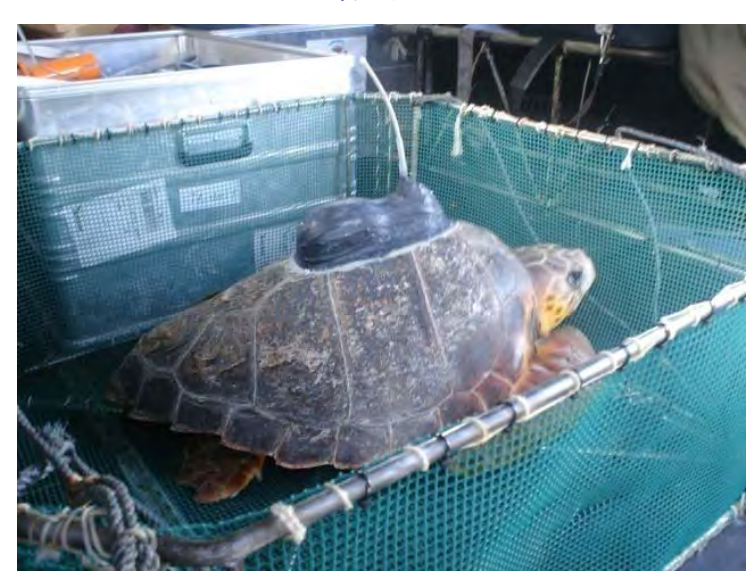

The integration spreads over the instrumental approach, because the aim is to add and make available the "in-situ" observations from both moored and drifting devices, on surface or undulate through the water column, and remote sensing as well. 


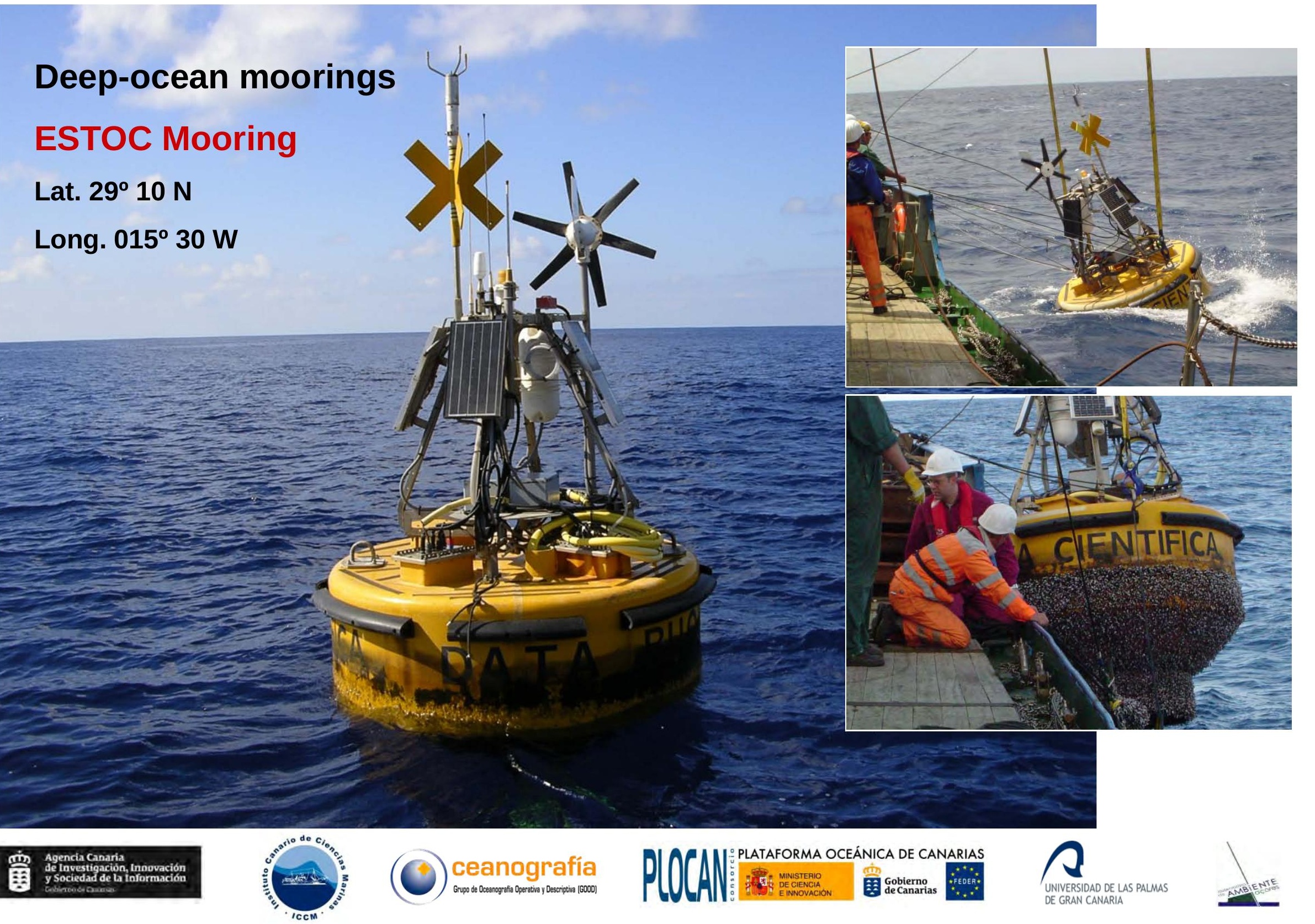




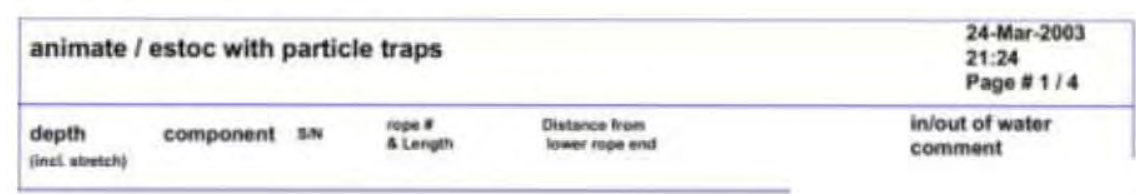

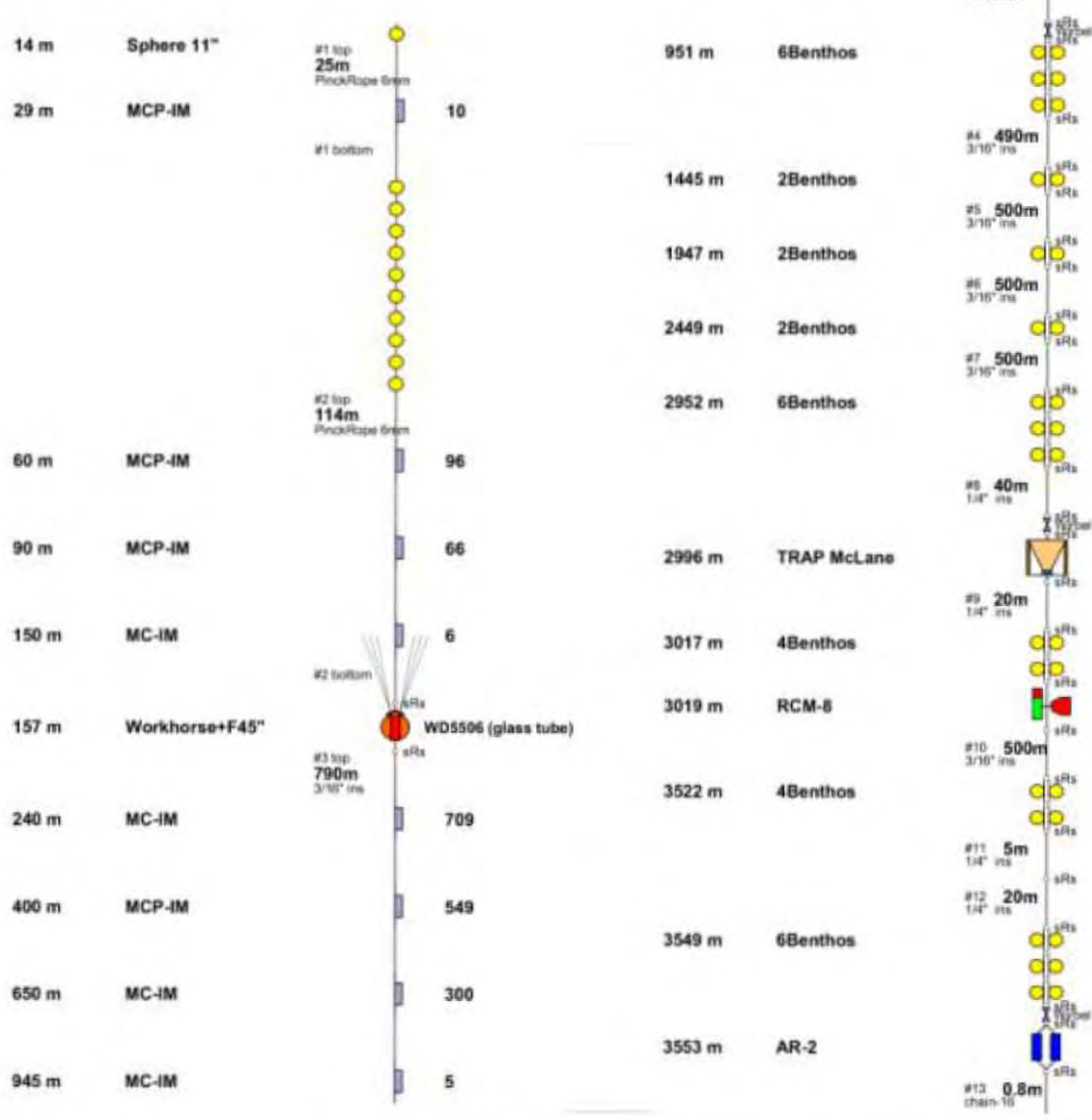
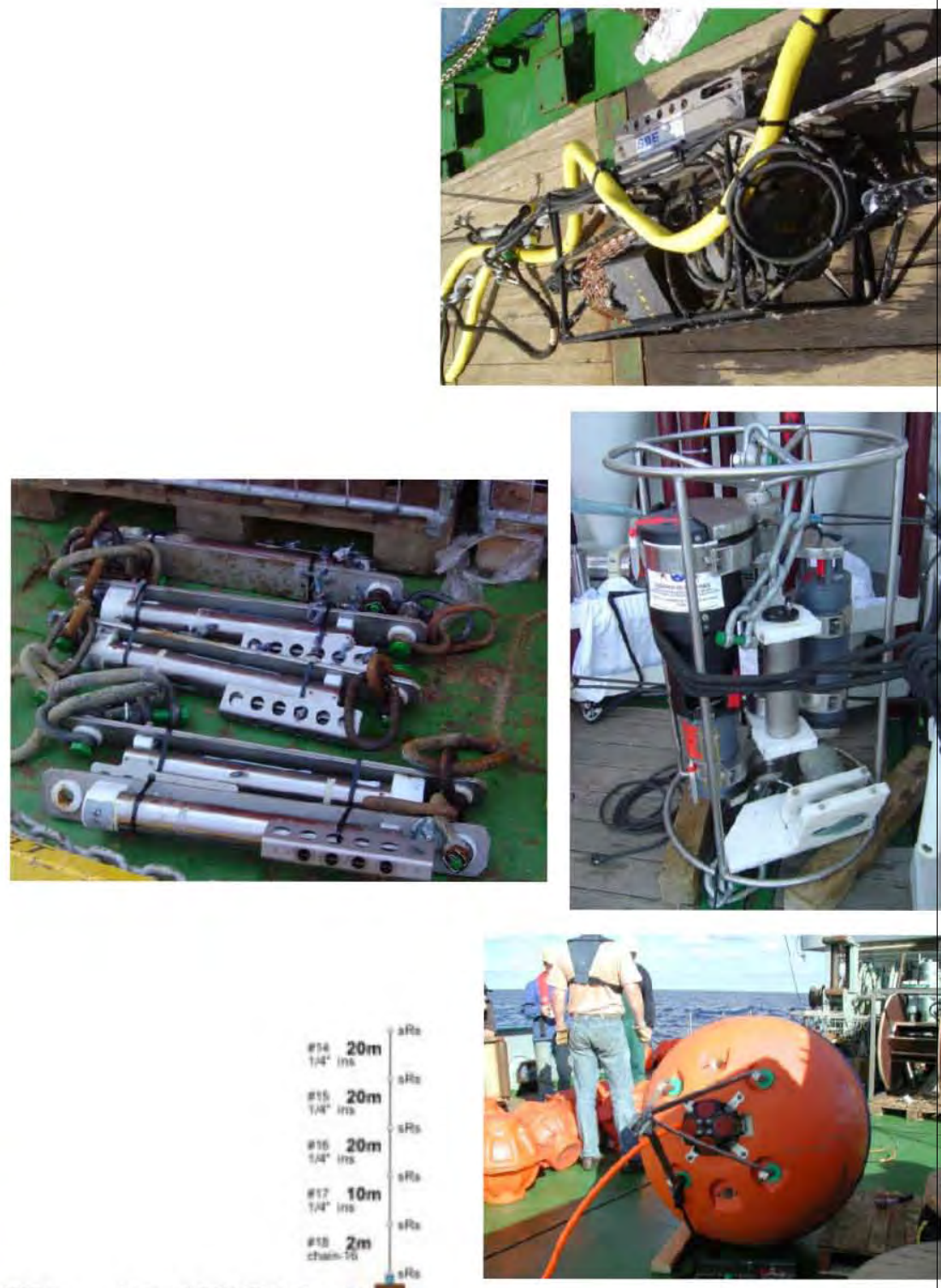

$3628 \mathrm{~m}$ Anchor $(4 \times 300) 1250 \mathrm{~kg}$ (didy weighth

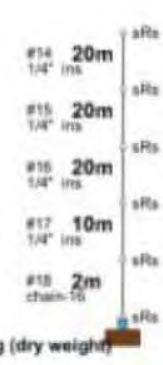

$\curvearrowright$

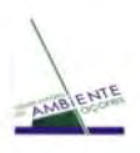




\section{Coastal moorings}

$\rightarrow$ Met: ws/wd, at, rh, ap, sr, GPS,

$\rightarrow$ Ocean: wt, c, do, hc, cs, cd, t..

- GSM/RF

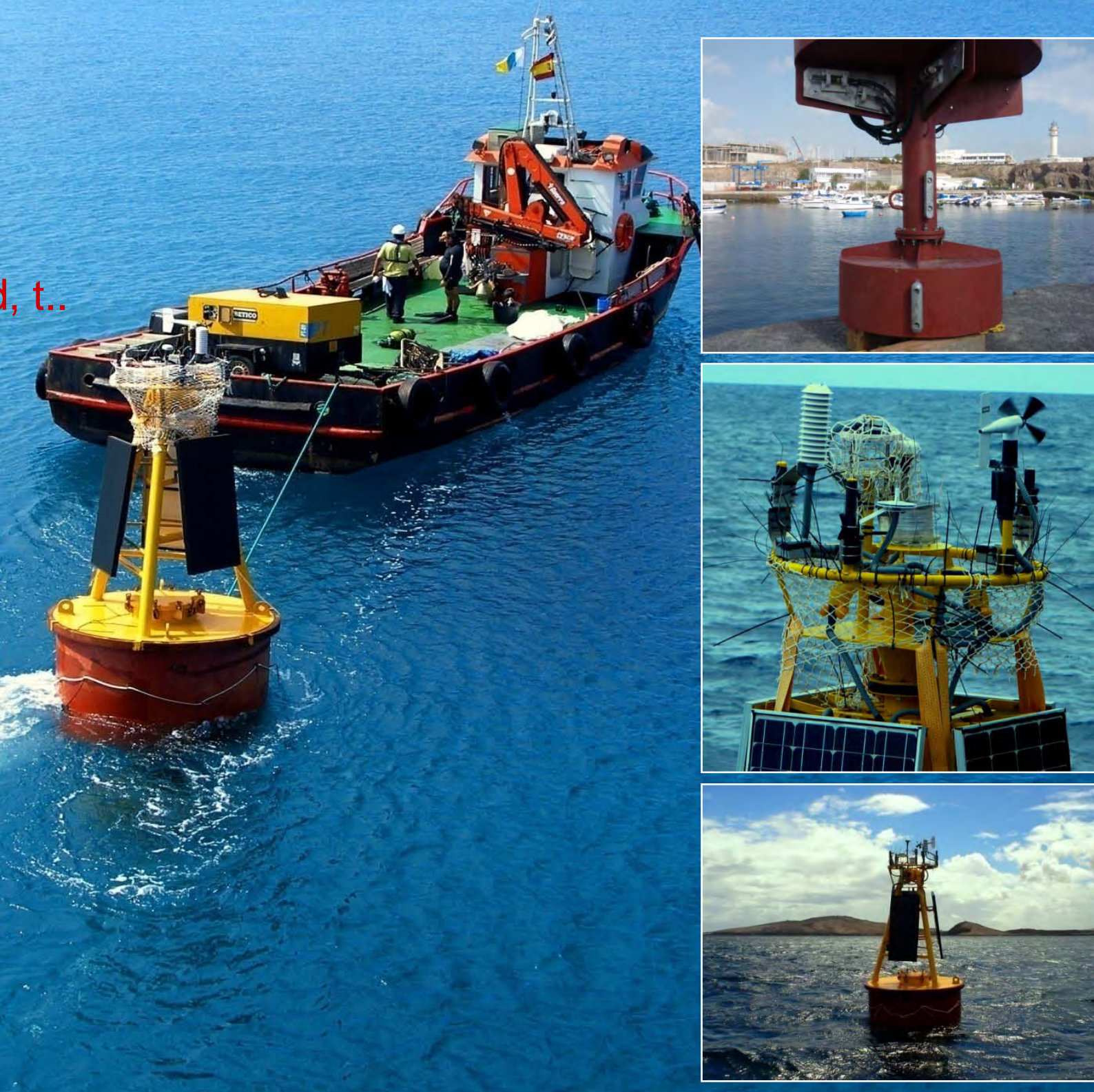

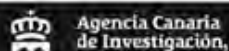




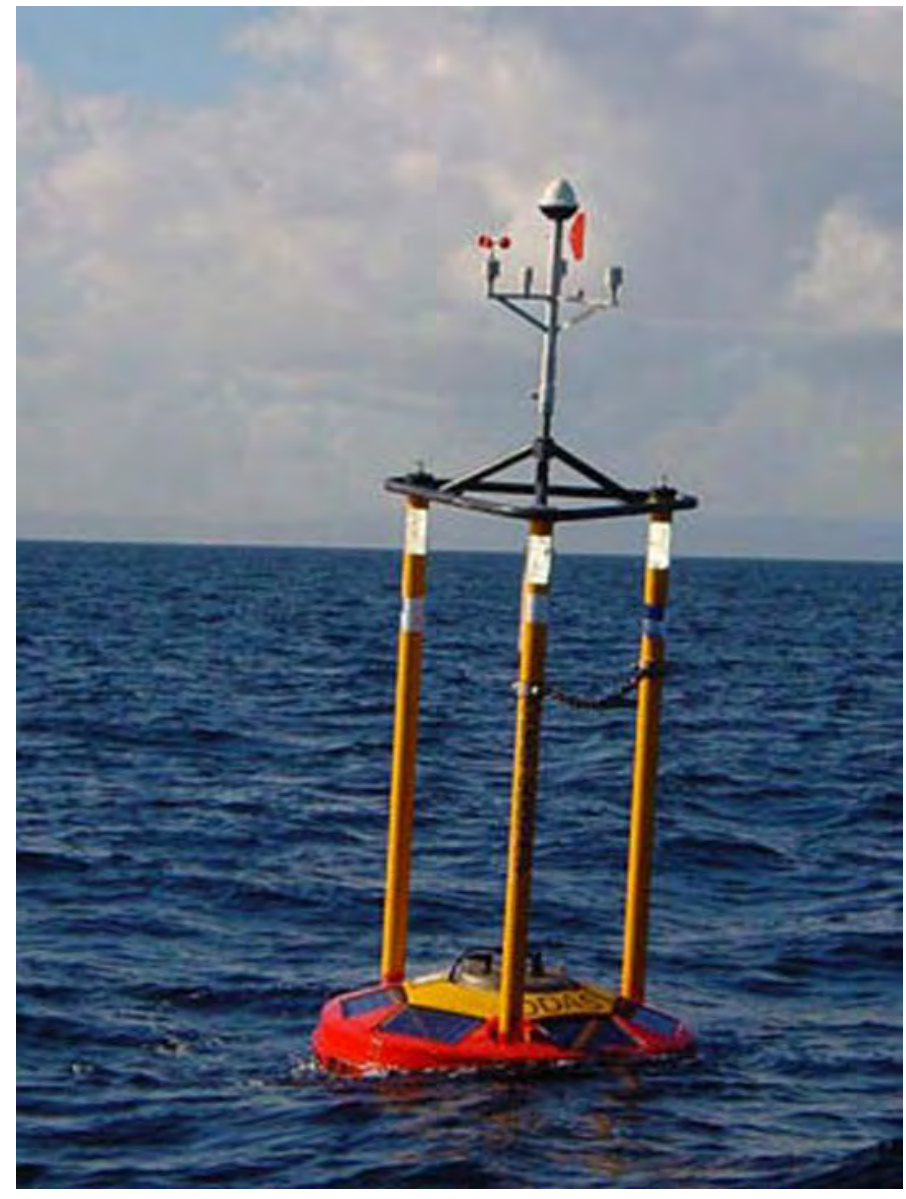

Spanish Deep-Water Monitoring Network

(Canary Islands)

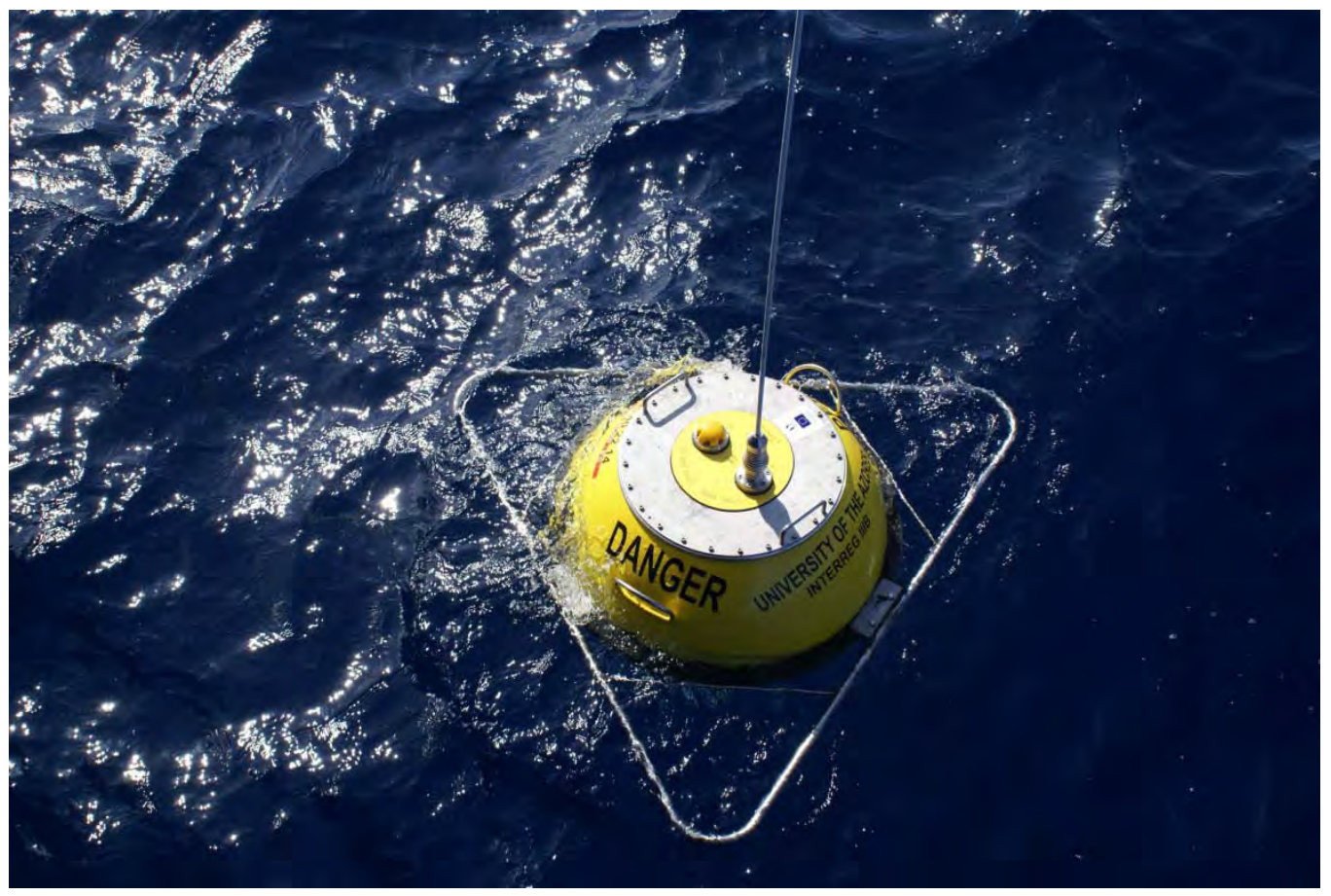

Datawell Network (Canaries, Madera and Açores Archipelagos) 
The obvious need to increase the acquired information quantity and quality, has involved directly the proposal with TECHNOLOGICAL DEVELOPMENTS on wide range of devices and tools, with the aim to bring out them more accessible both technically and economically. 


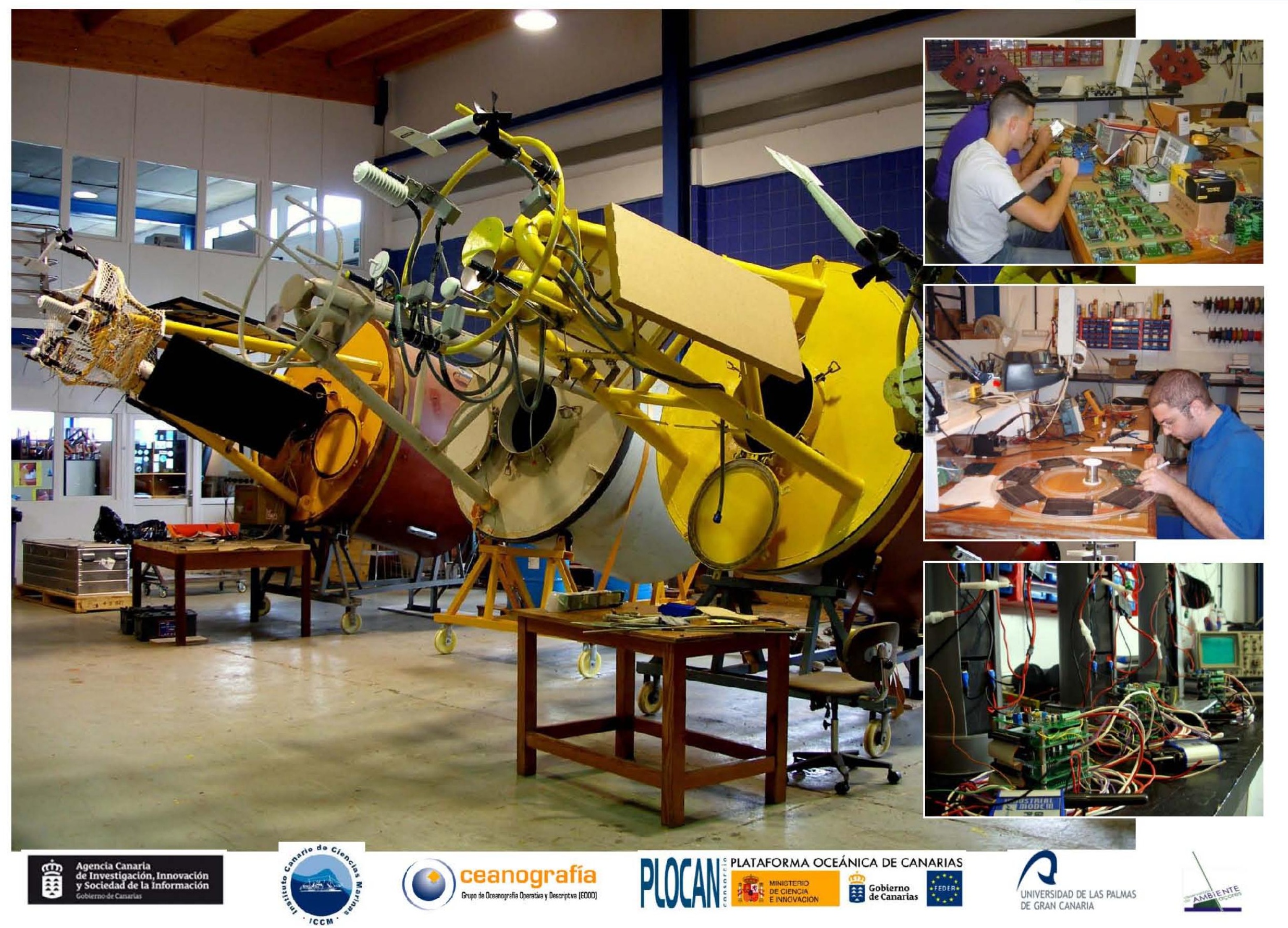



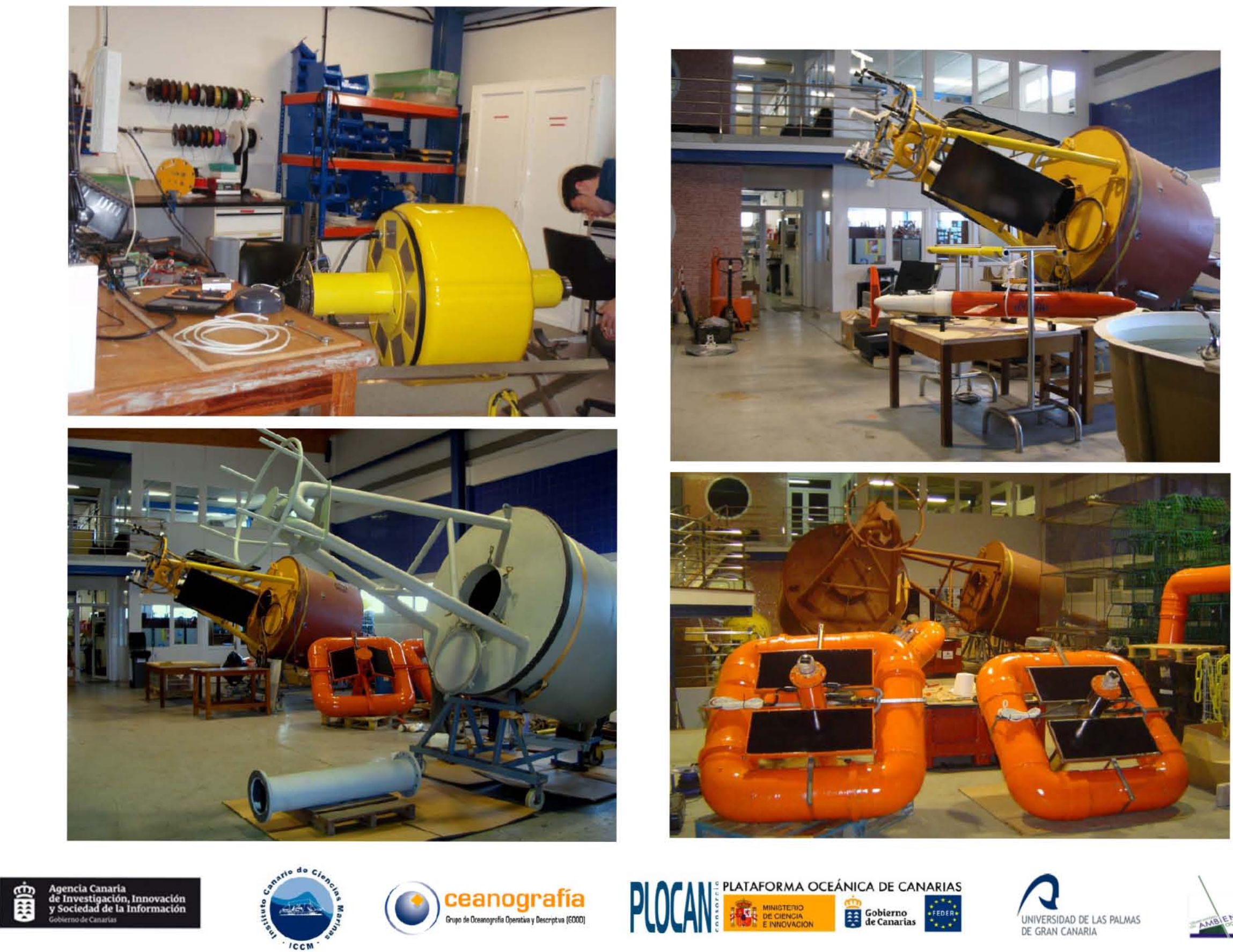

(1) ceanografía

PUCA PLATAFORMA OCEÁNICA DE CANARIAS

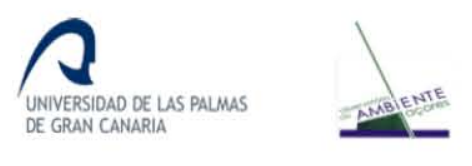




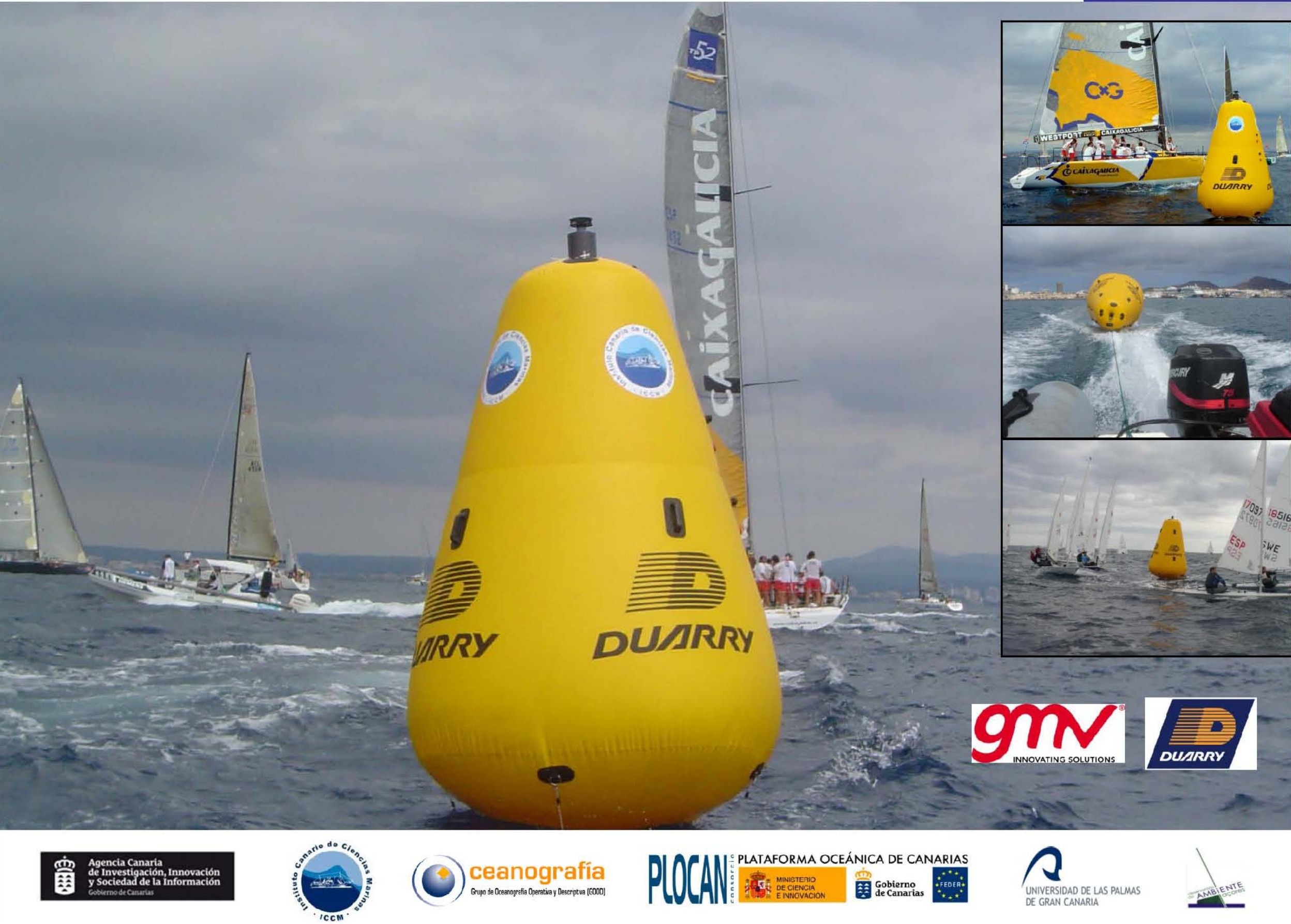




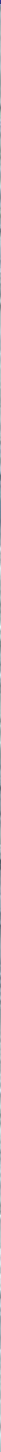

\section{Agreement with NOAA since 1998.}



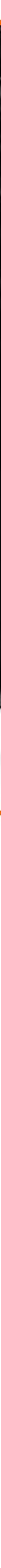

POCAN
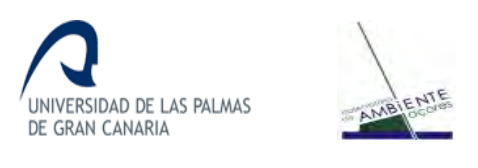


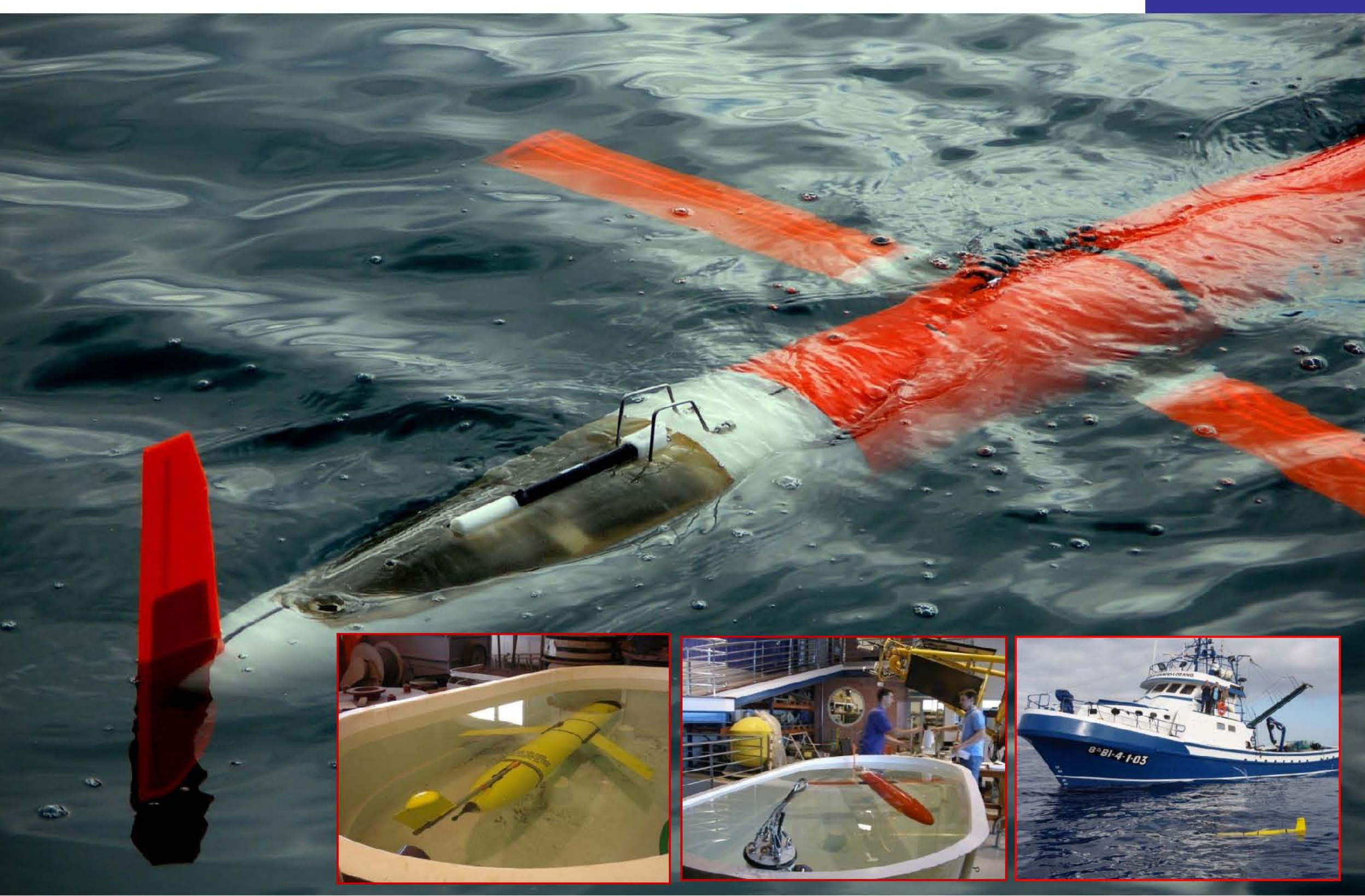

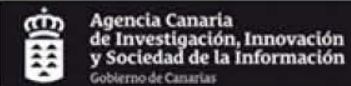


Transects between shore and ESTOC site $(100 \mathrm{~nm})$ and Gran Canaria and Morocco coast

賟 Agencicicinartis

苟 


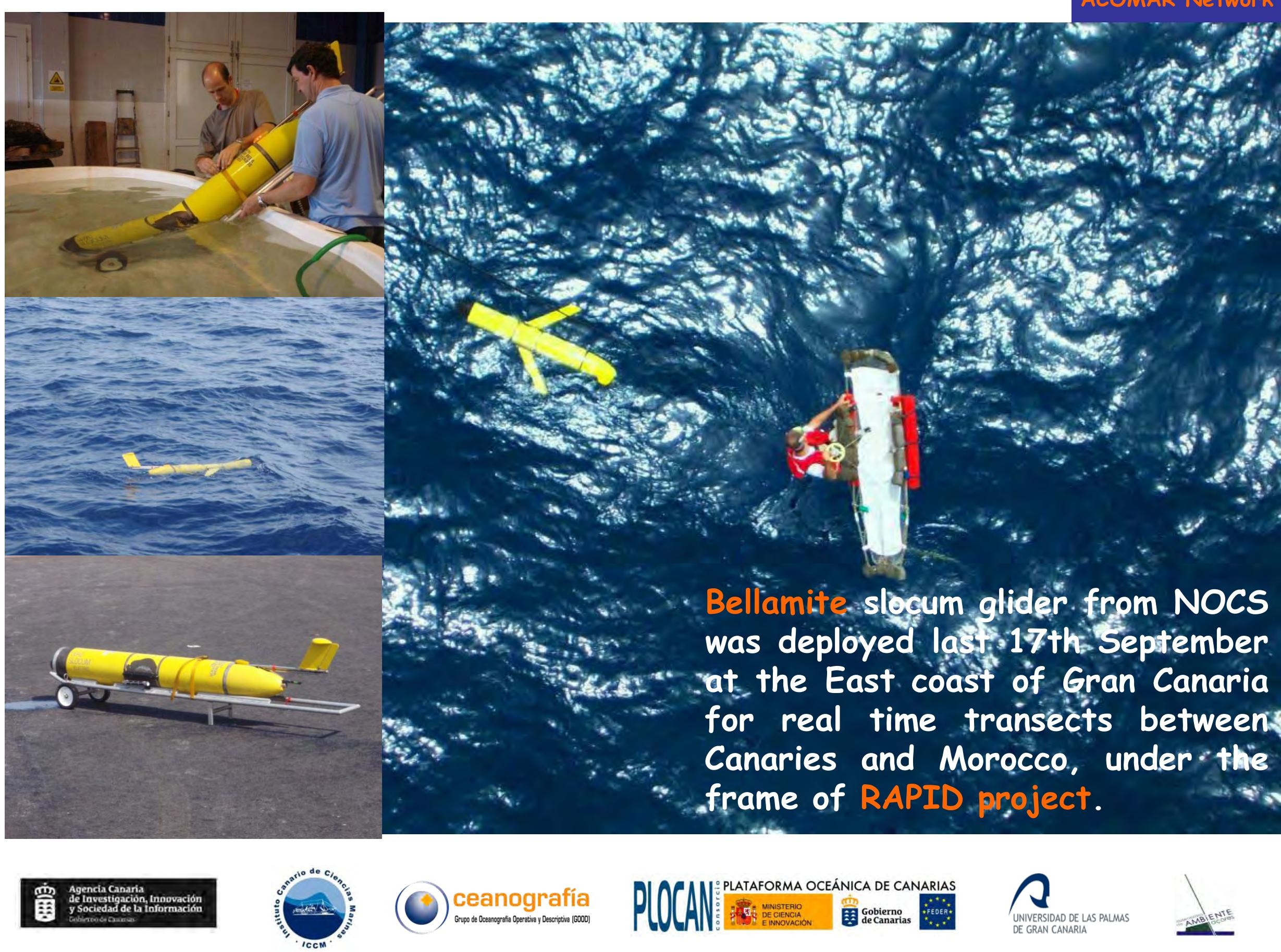




\section{Partnership RU COOL and PLOCAN - Transatlantic glider Missions}

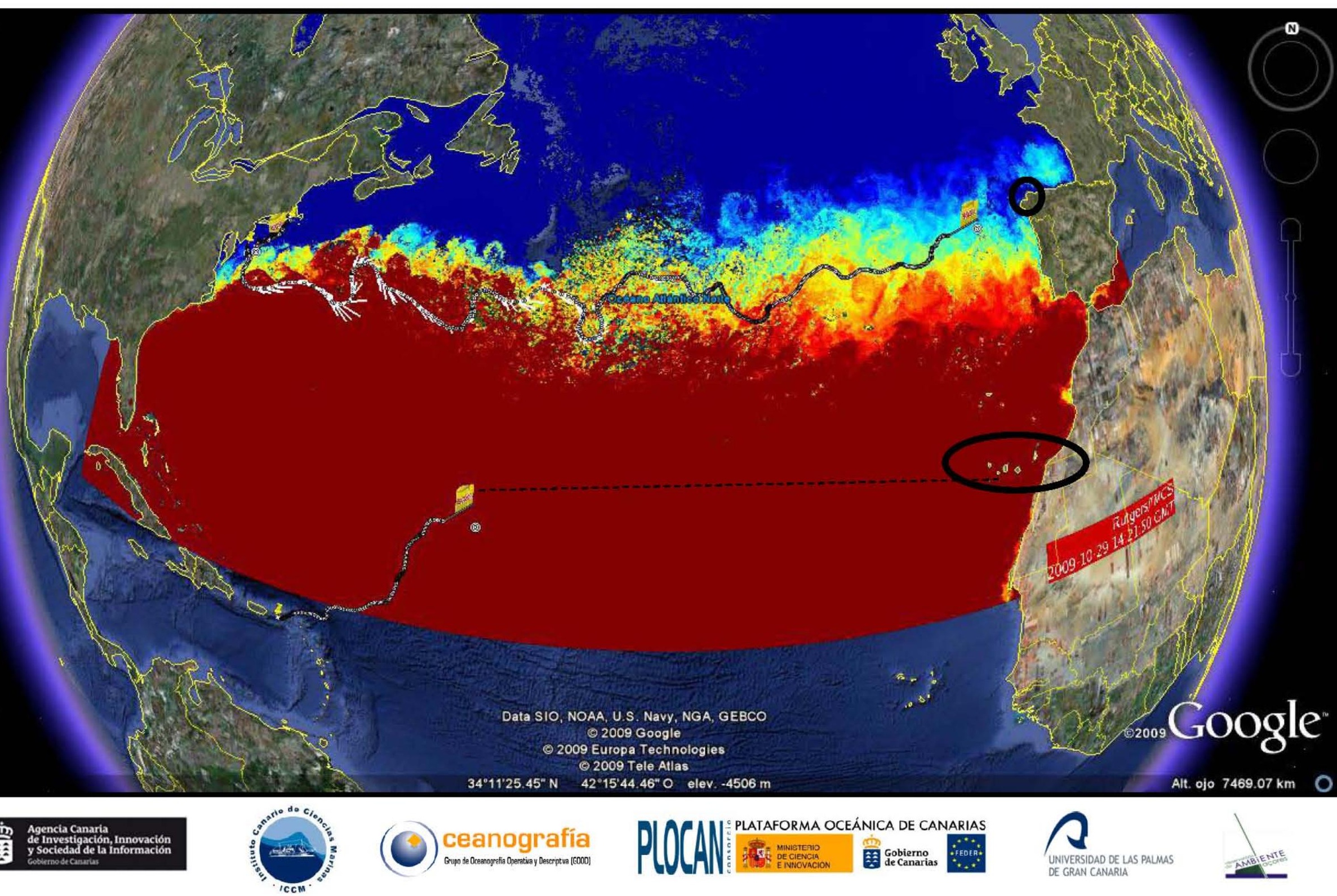


ACOMAR Network

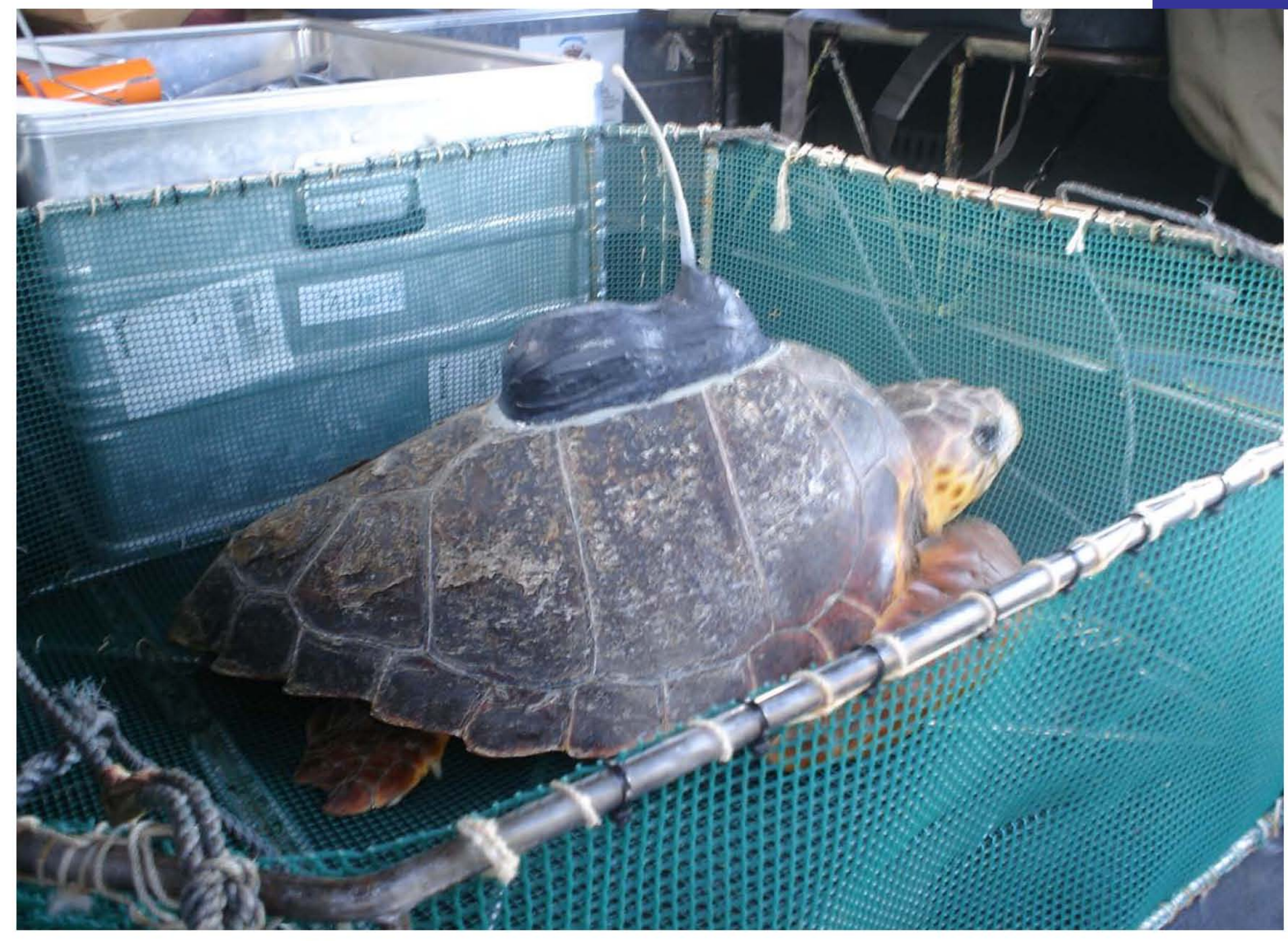

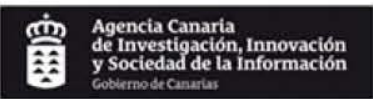

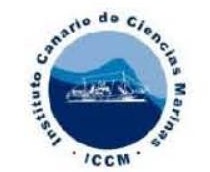

(3) ceanografía

P)

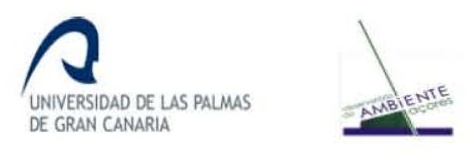




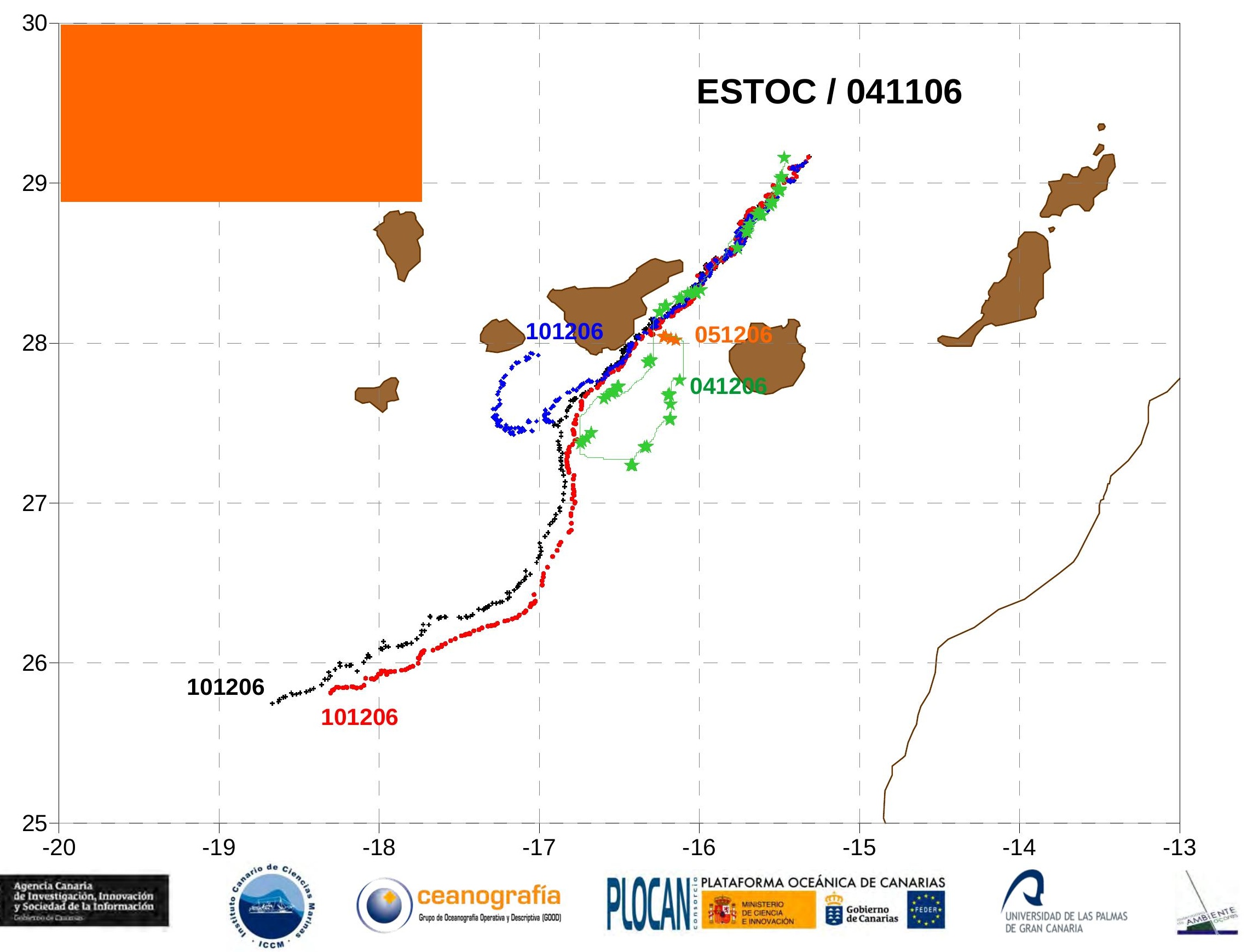




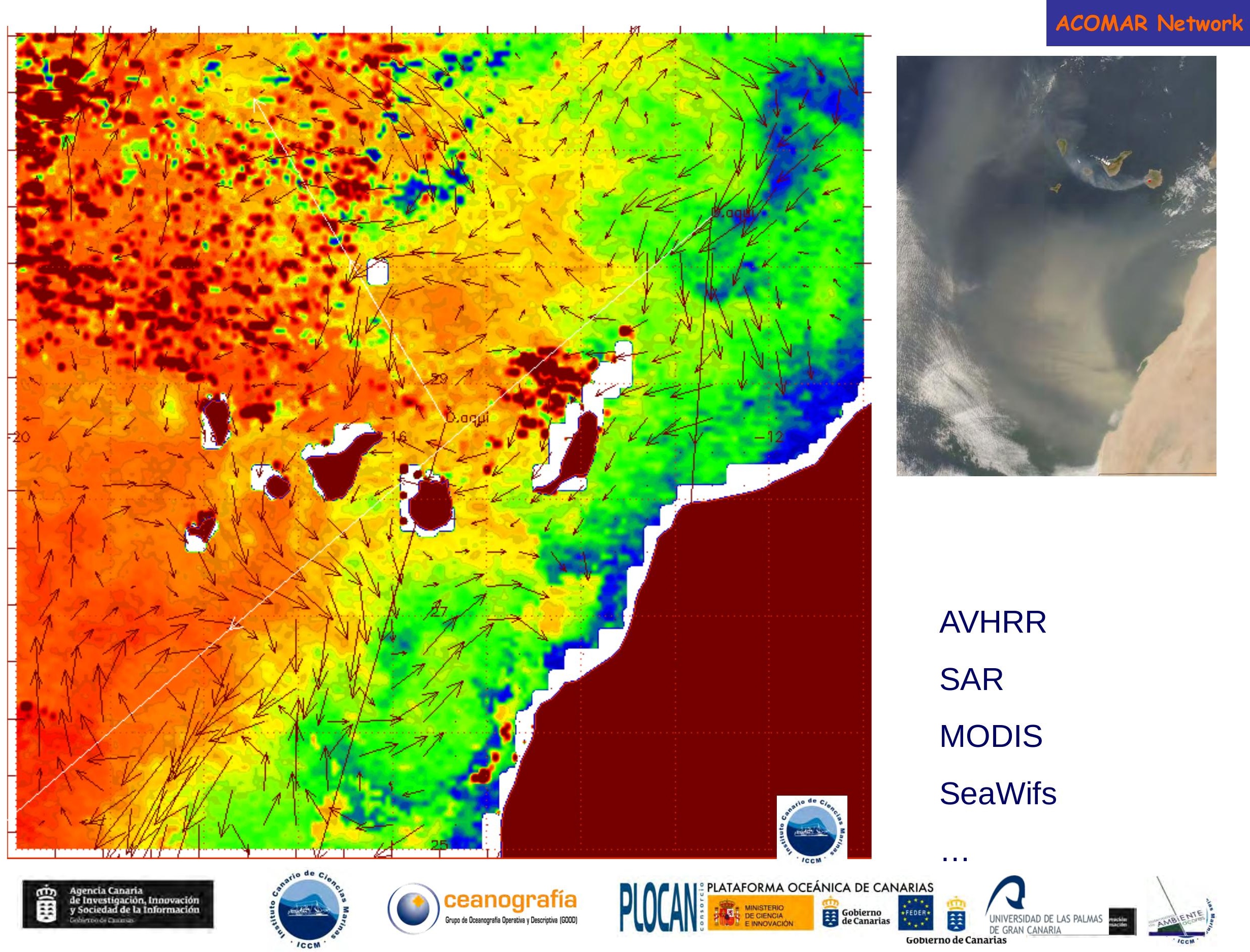



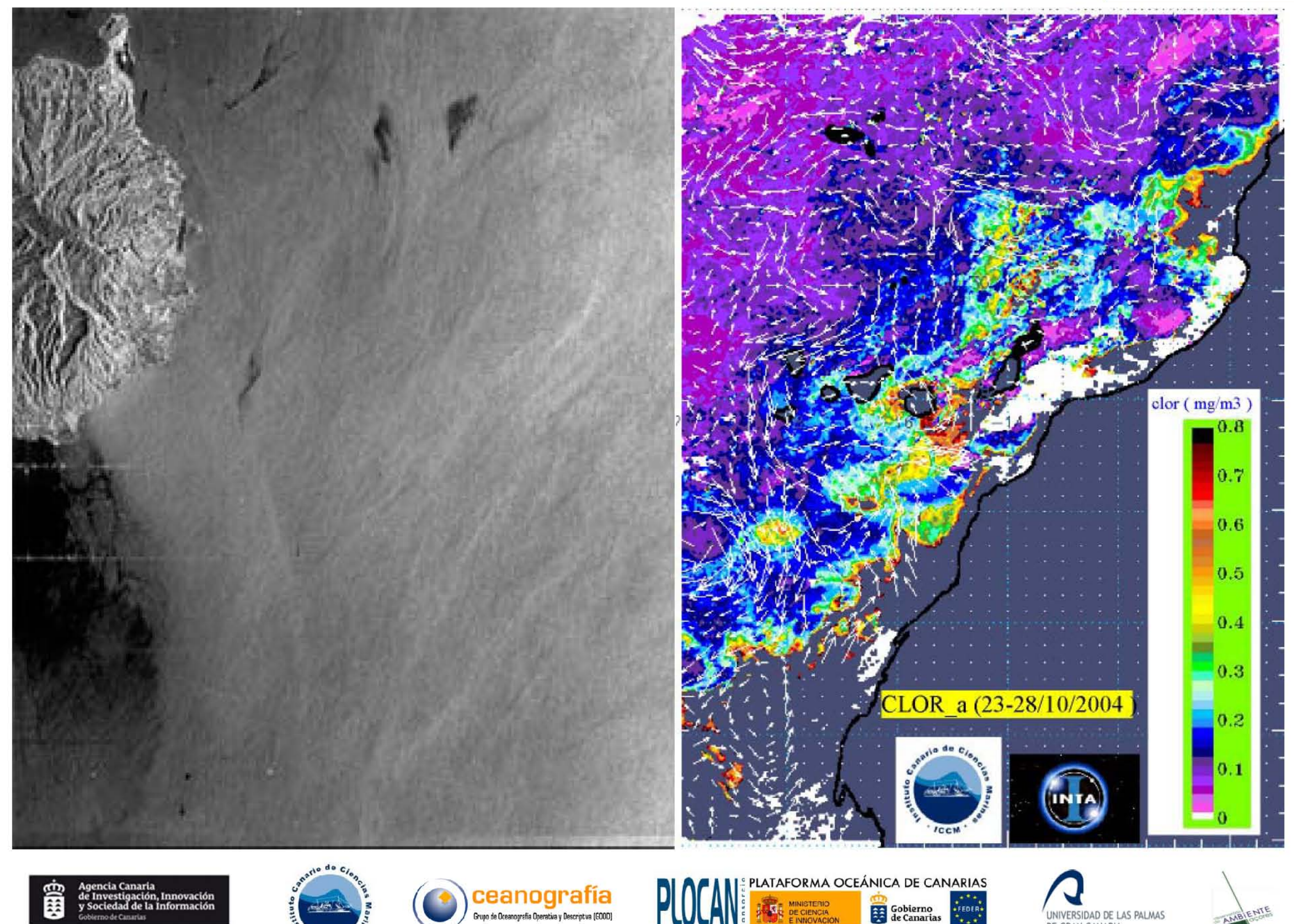

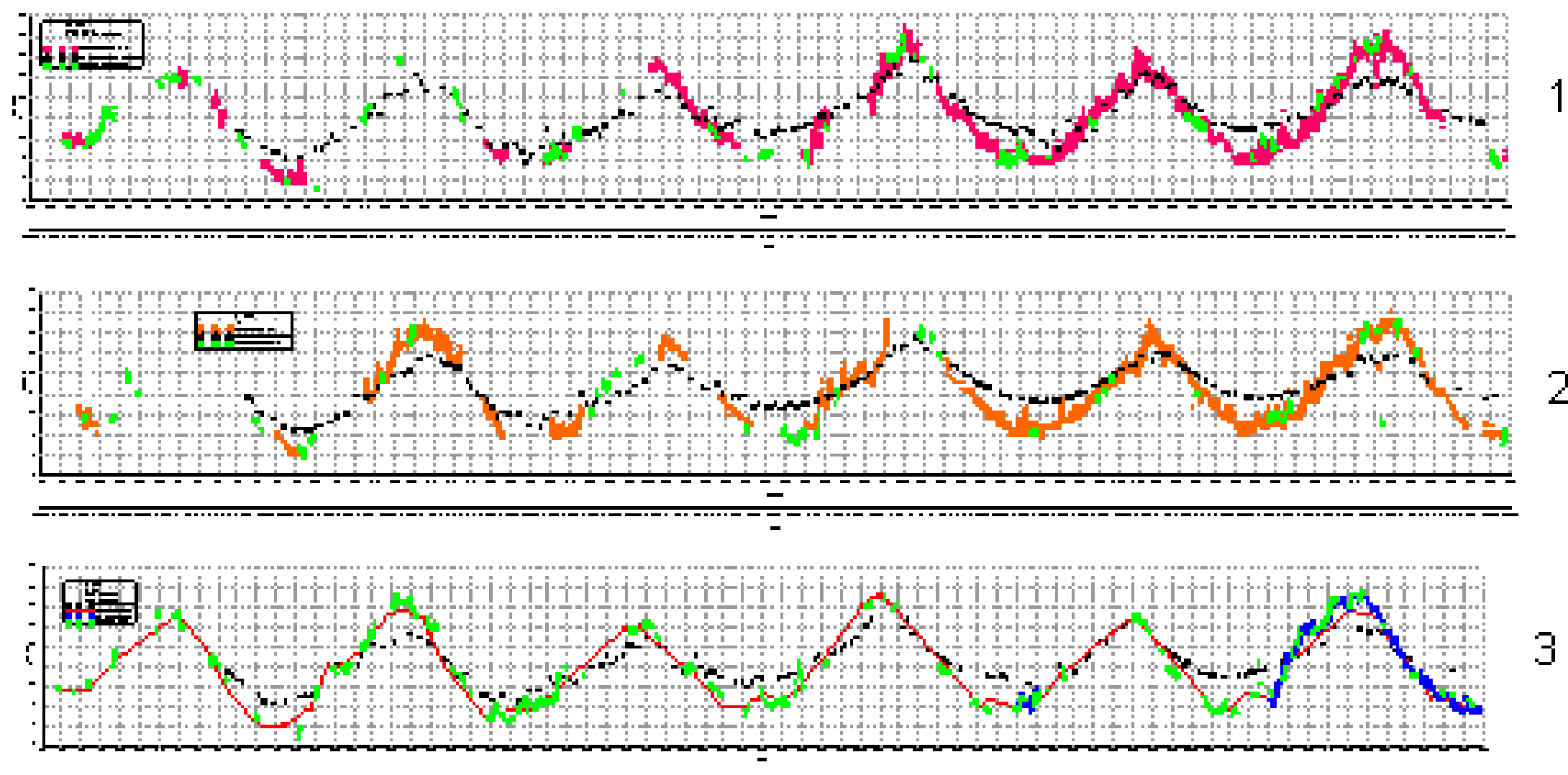

6-years SST time-series at three different sites around Canaries. (1) NE-Gran Canaria; (2) SE Tenerife and (3) ESTOC.
Moored Buoy
AVHRR
- Moored Buoy
- NOAA drifter
Moored Buoy

CTD cast 


\section{DELTA Tropical Storm. Canary Islands. November 2006}

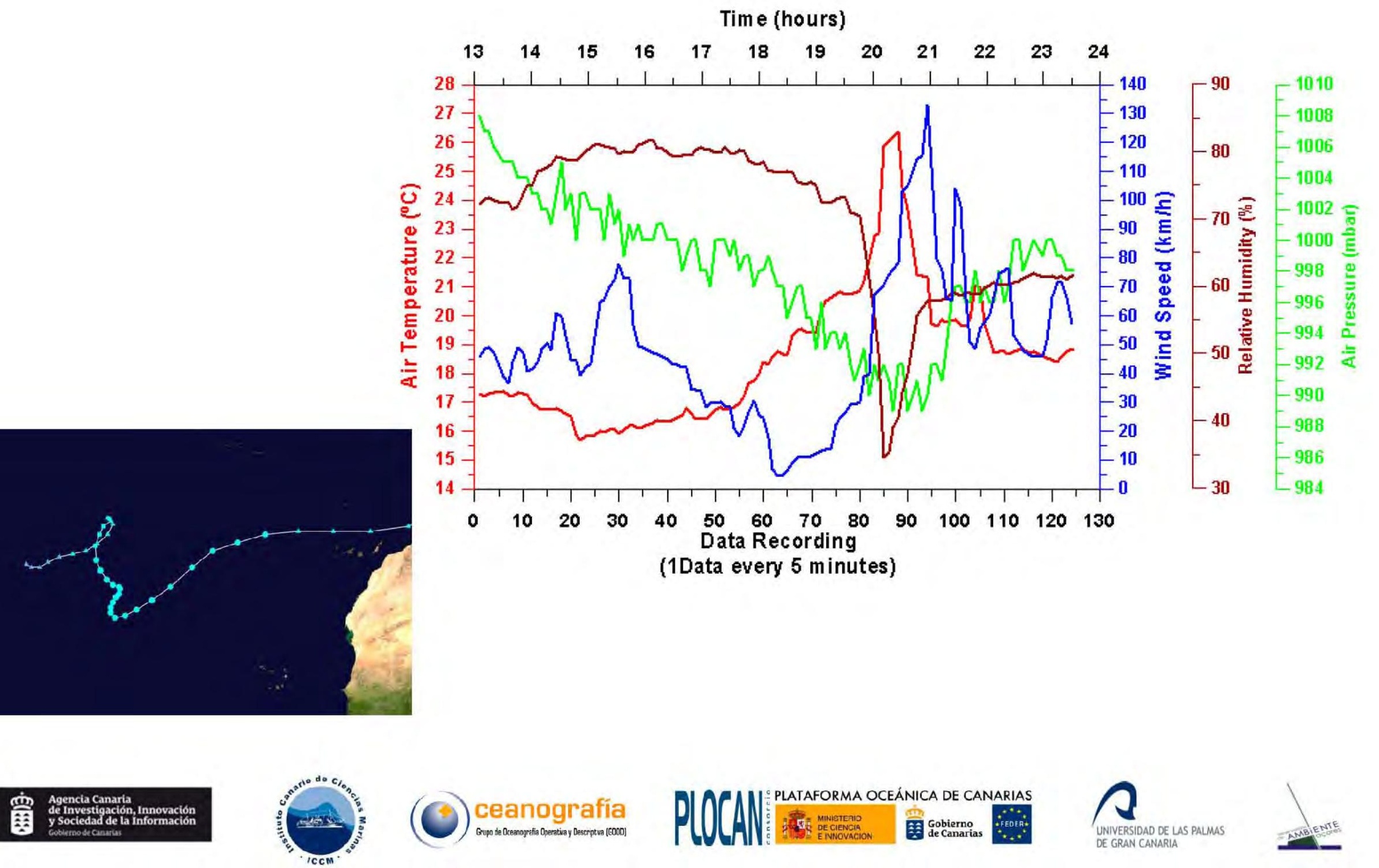




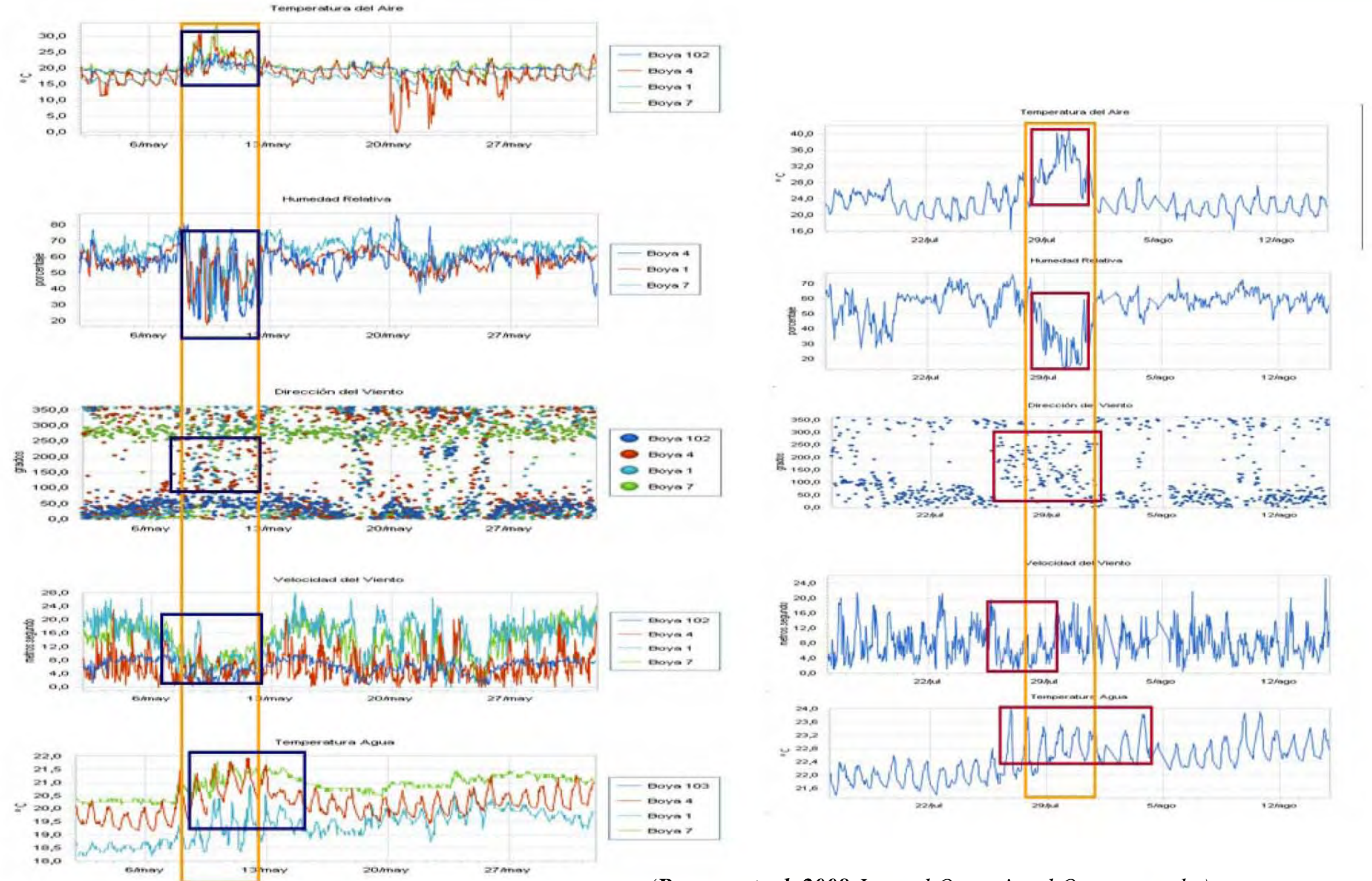

(Barrera et al. 2008 Journal Operational Oceanography)
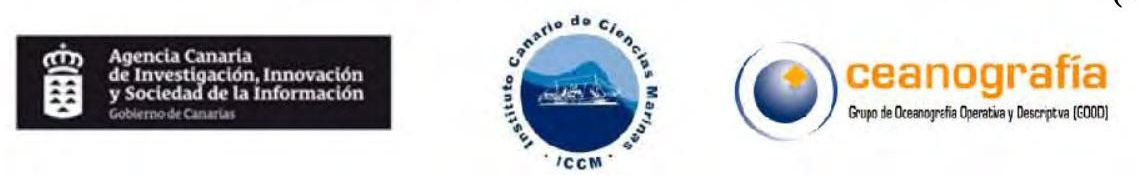

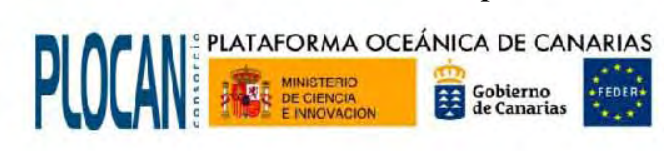
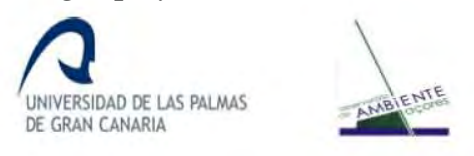


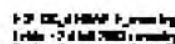
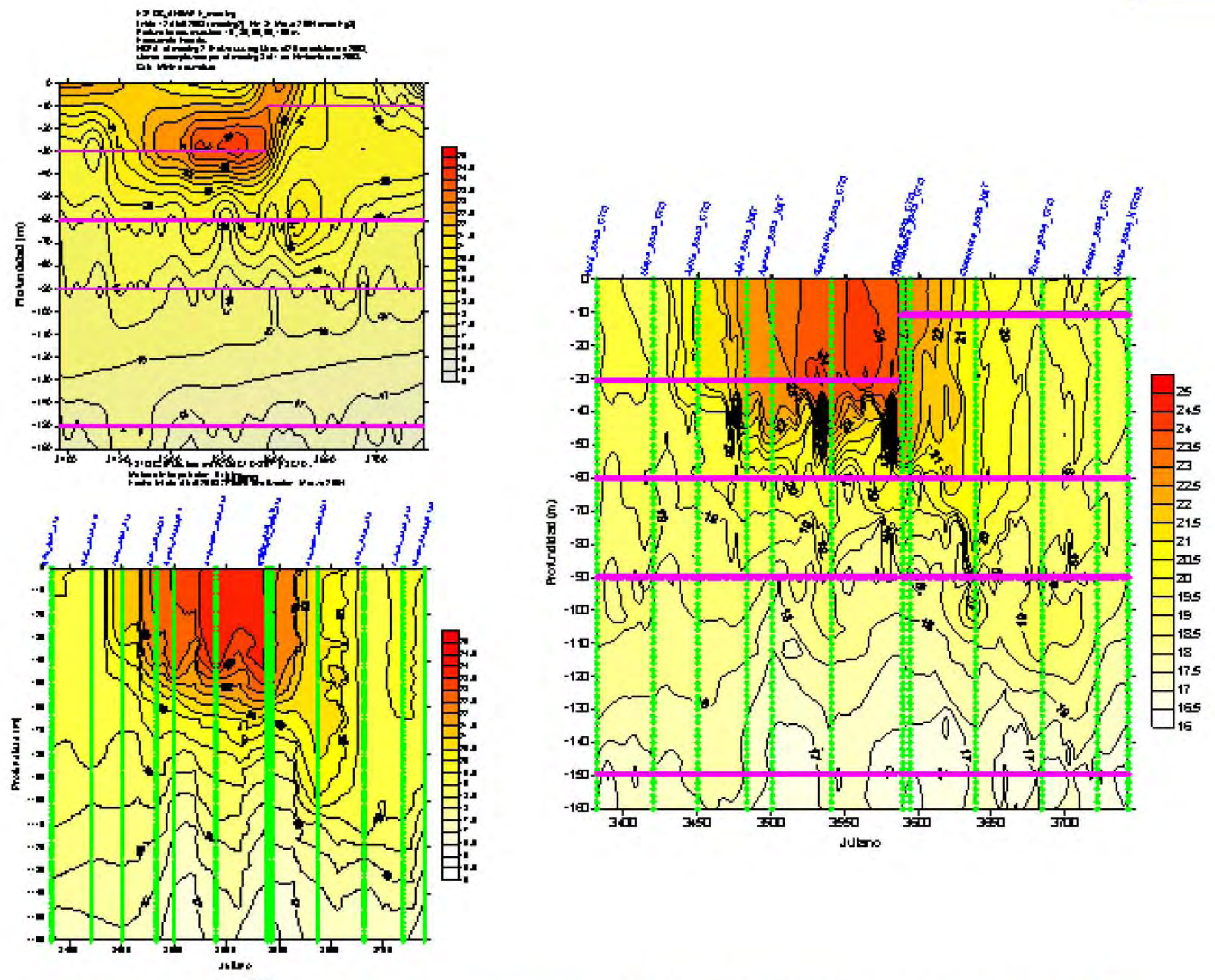

35
245
24
25
27
255
22
215
21
915
19
155
19
155
18
175
17
155
15 


\section{www.oceanografiaiccm.es}

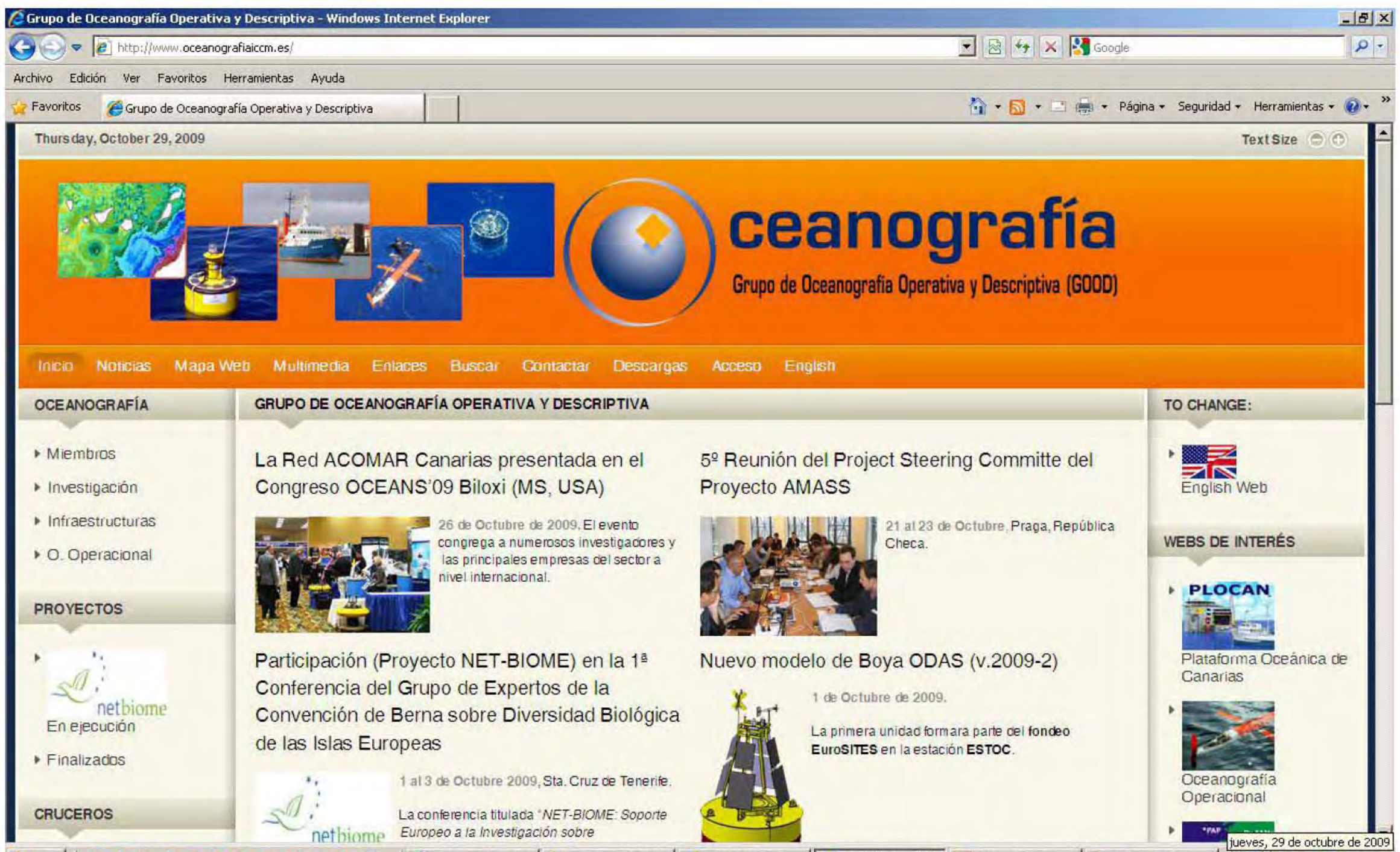

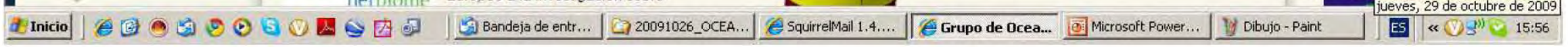
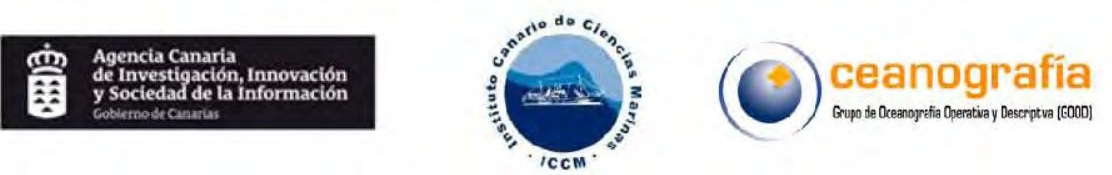


\section{www.plocan.eu}

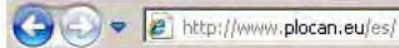

$7 \sqrt{6} \times \sqrt{9 \text { Google }}$

Archivo Edición Ver Favoritos Herramientas Ayuda

Eliz Favoritos Plataforma Oceánica de Canarias

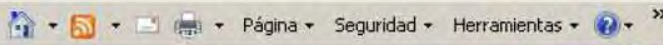

PlOCAN

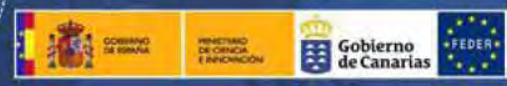

Inicio Noticias Enlaces ICTS Mapa Web Descargas Buscar Contactar English

\begin{tabular}{l|l} 
PLOCAN & PLATAFORMA OCEÁNICA DE CANARIAS
\end{tabular}

- Descripción

- SI.G PLOGAN

+ Cronologia

- Financiación

- Consorio

- Colaboradores

- Divulgación

- Pertil del contratante

PROYECTOS

- MaRes

- WELCOM̃

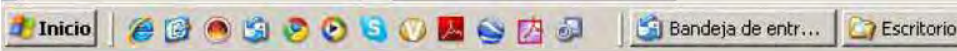

Visita al National Data Buoy Center (NDBC) de la NOAA en Mississippi (USA)

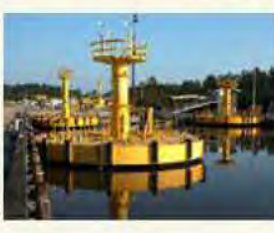

Reunión de Constitución del Comité de actividades socioeconómicas de PLOCAN

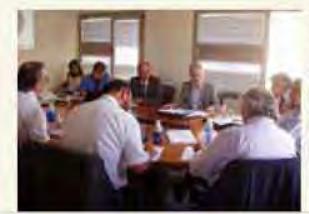

9-10-2009. Por unanmidad se eligb a D. José Regidor. Rector de la Universidad de Las Pamas de Gran Canaria, como

presidente y a D. Arturo González Drector General de la Fundación INNOVAMAR como secretario.
La Provincia, 25/10/2009: Entrevista a Dña Cristina Garmendia, Ministra de Ciencia e Innovación.

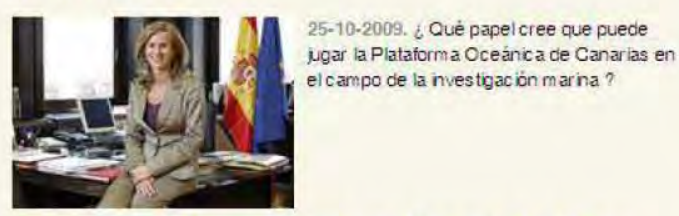

Consejo de Ministros en Las Palmas de Gran Canaria

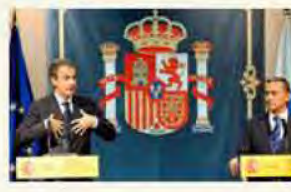

9-10-2009. El Consejo de Minstros celebró Una reunión extraorcinaria el dia 9 de octubre en Las Pamas de Gran Canaria. t5a

RUTGERS UNIVERSITY .

RU TGERS UNIVER |e Squirrel|Mail 1.4.... Plataforma Oc...

VIDEO DE PRESENTACIÓN

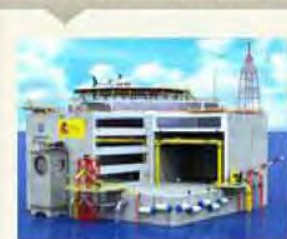

BOYA ODAS - PLOCAN

- Fondeo ODAS - PLOCAN

,

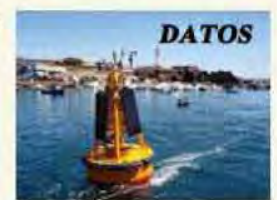
ES «QD) $15: 58$ 
The network has been build from up to down, starting from SPECIFIC FINAL USERS towards general users, and at the same time, holding the aims established by national and international agencies and organizations, focused on to understand the processes and phenomena at global scale.

- Harbours (commercial and sportive).

- Sailing and Fisher Community.

- Aquaculture (Fish-farming).

- Windsurf riders community.

- Tourist and local beach users.

- Search and Rescue Agency (SAR).

- Military.

- Scientific community.

- Government agencies.

-... 


\section{Harbours}

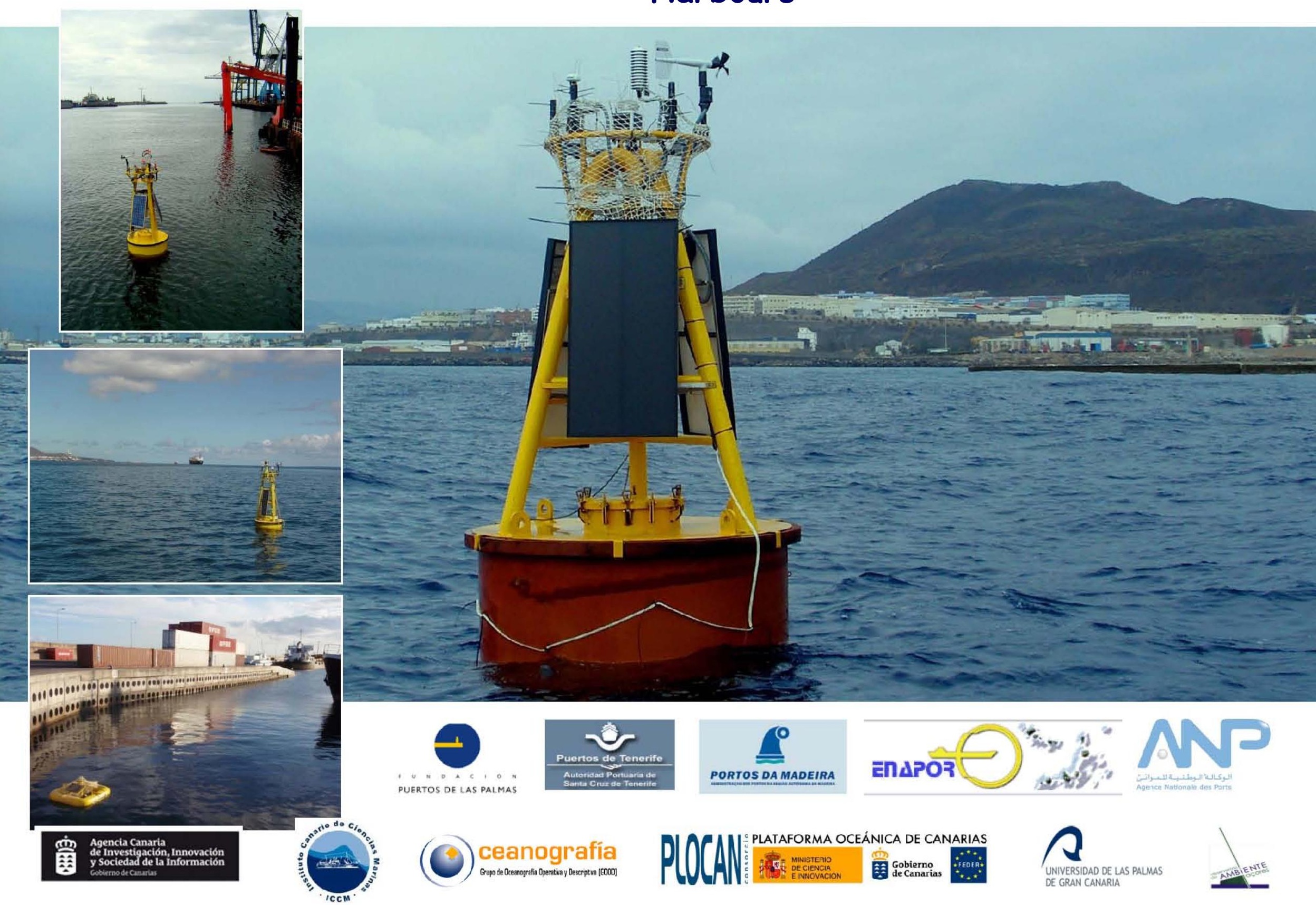



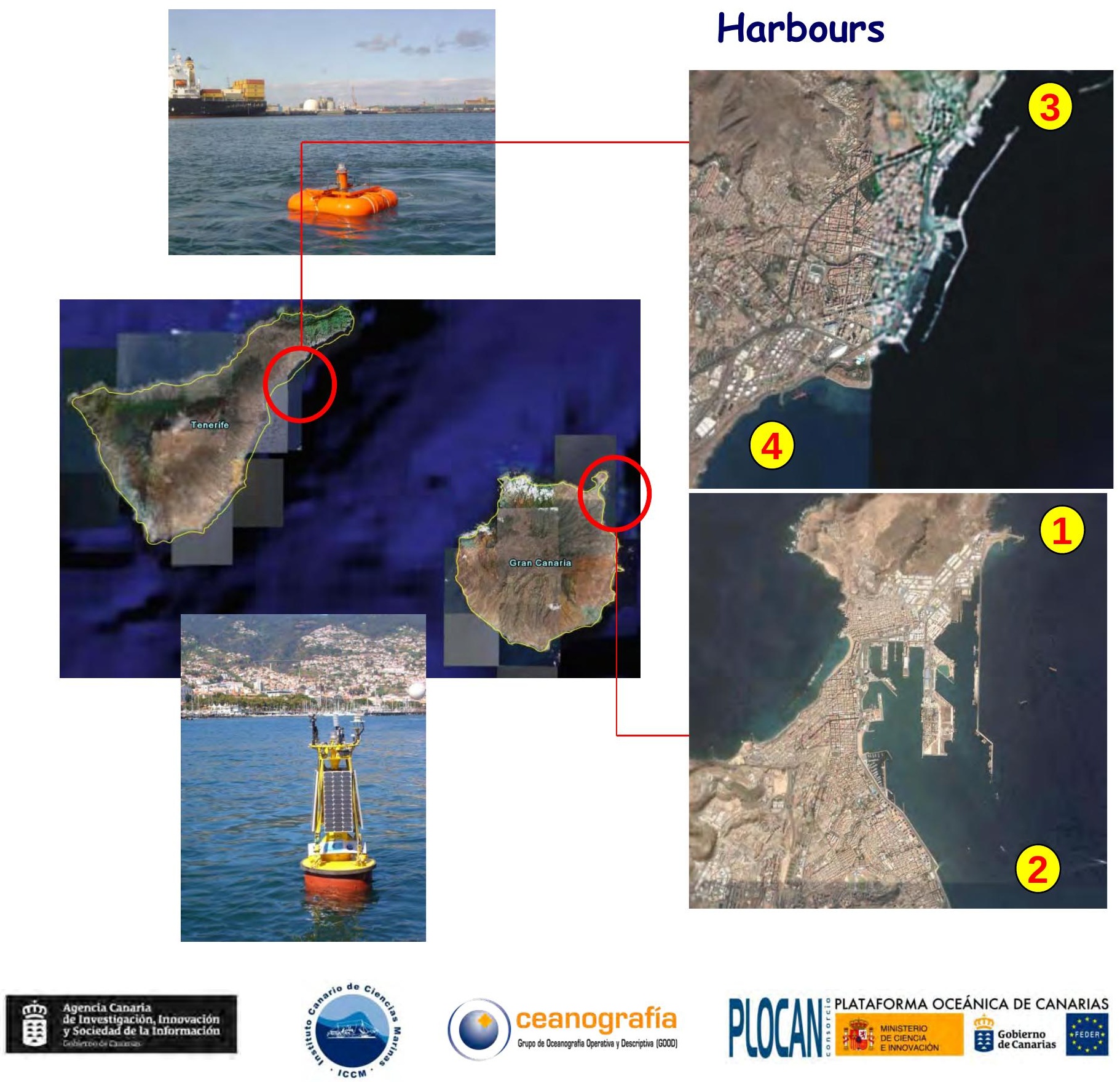

(D) ceanografía

PIOCAN

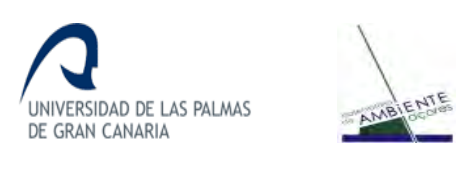




\section{Harbours}

\section{Valencia's Harbour Autho}
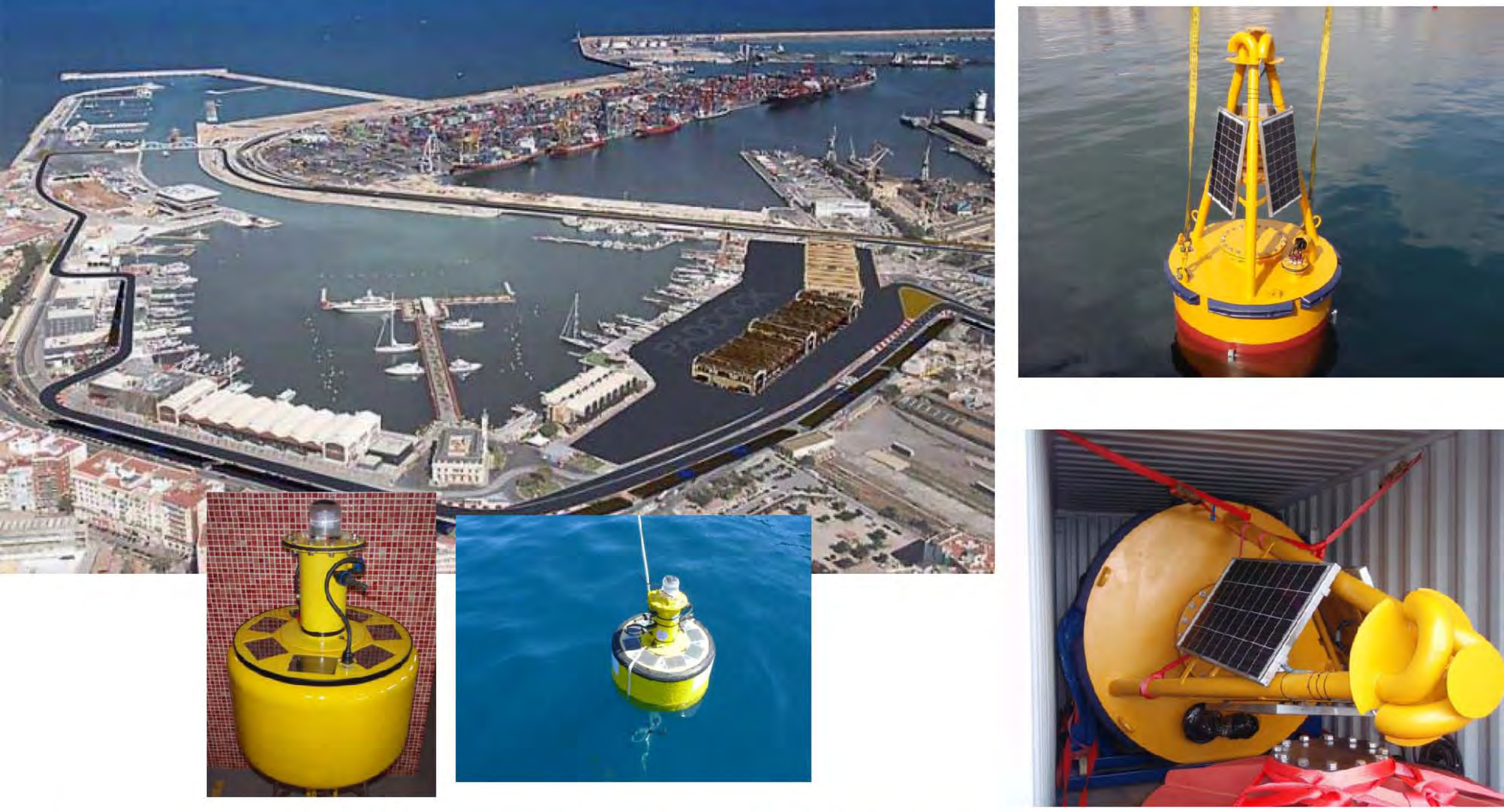


\section{Aquaculture- Fishfarming}

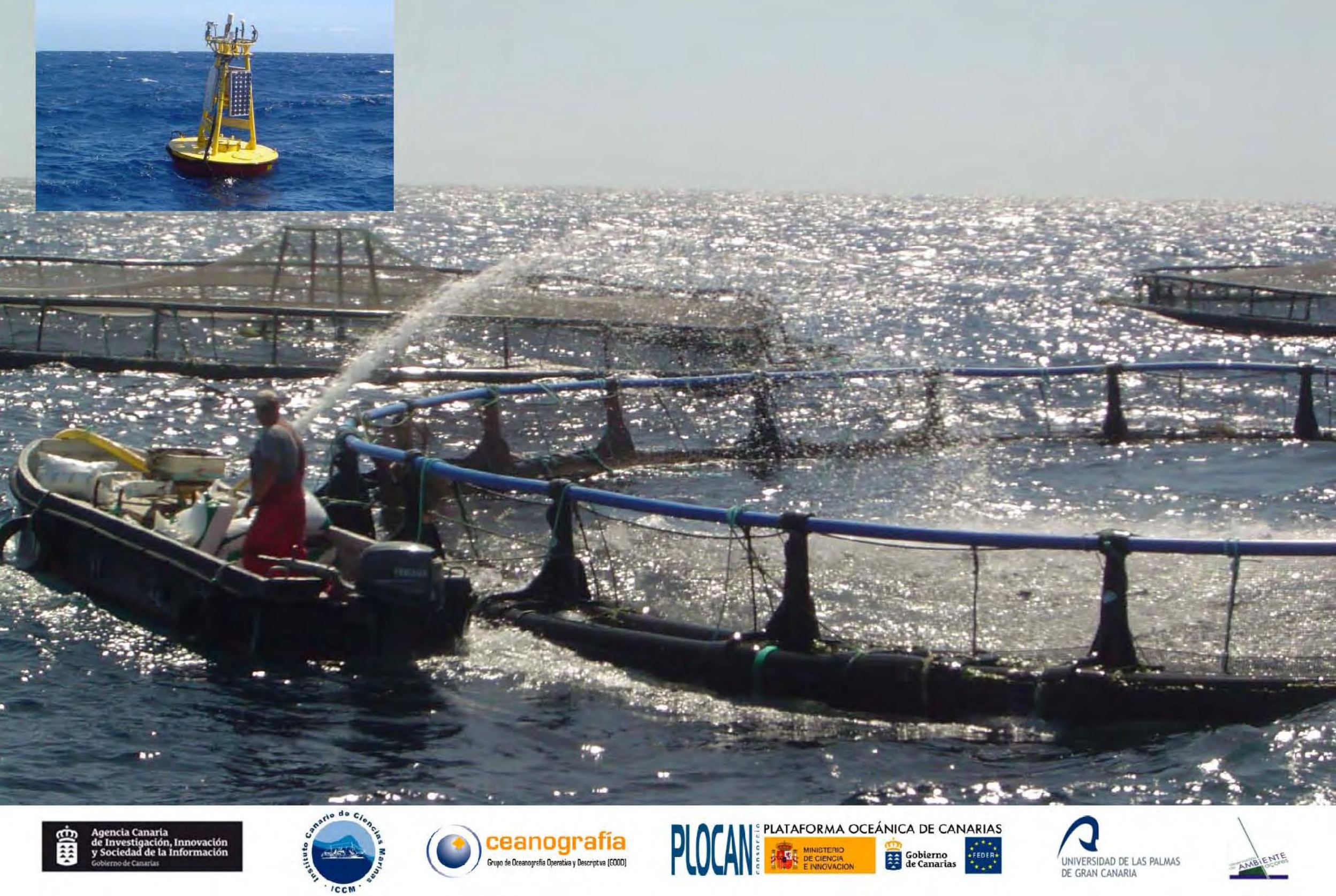




\section{Marine Protected Areas}

- Garajau (Madeira. PT)

- Illes Medes. (Girona. SP)

Generalitat de Catalunya Departament de Medi Ambient i Habitatge

Área Protegida de les Illes Medes
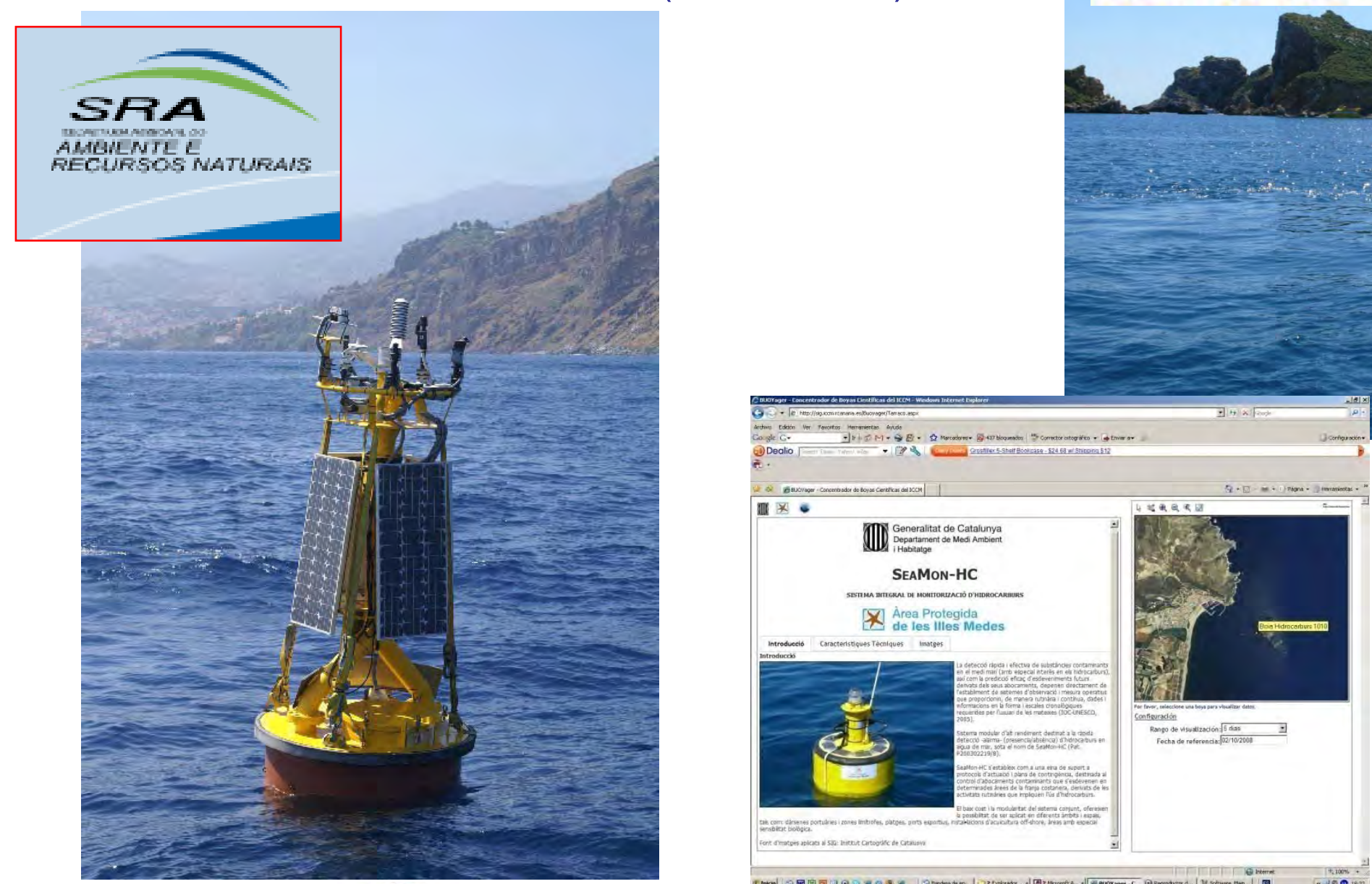

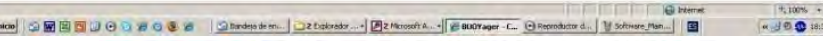




\section{Search and Rescue}
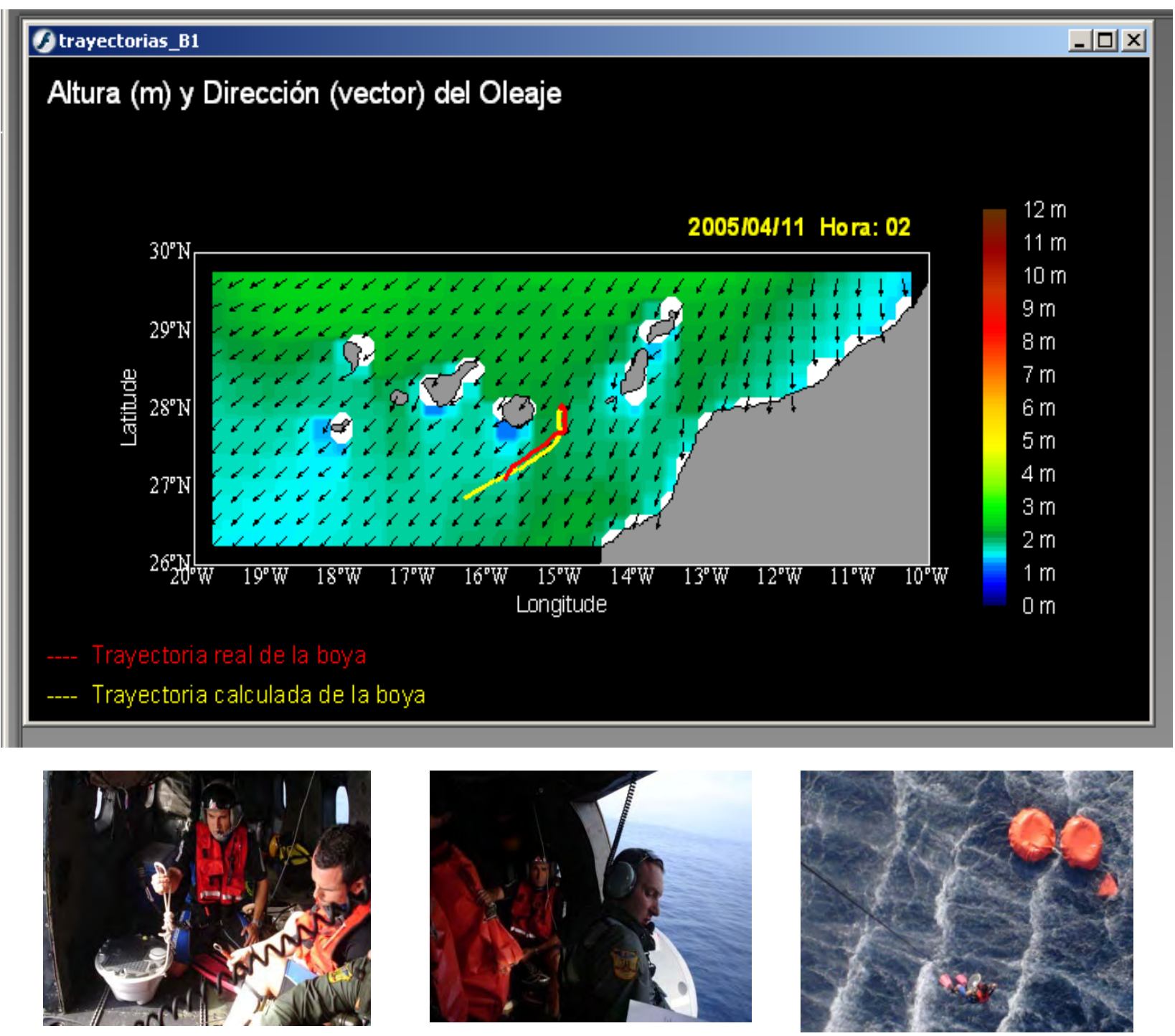

\section{Theoretical and real exercises.}

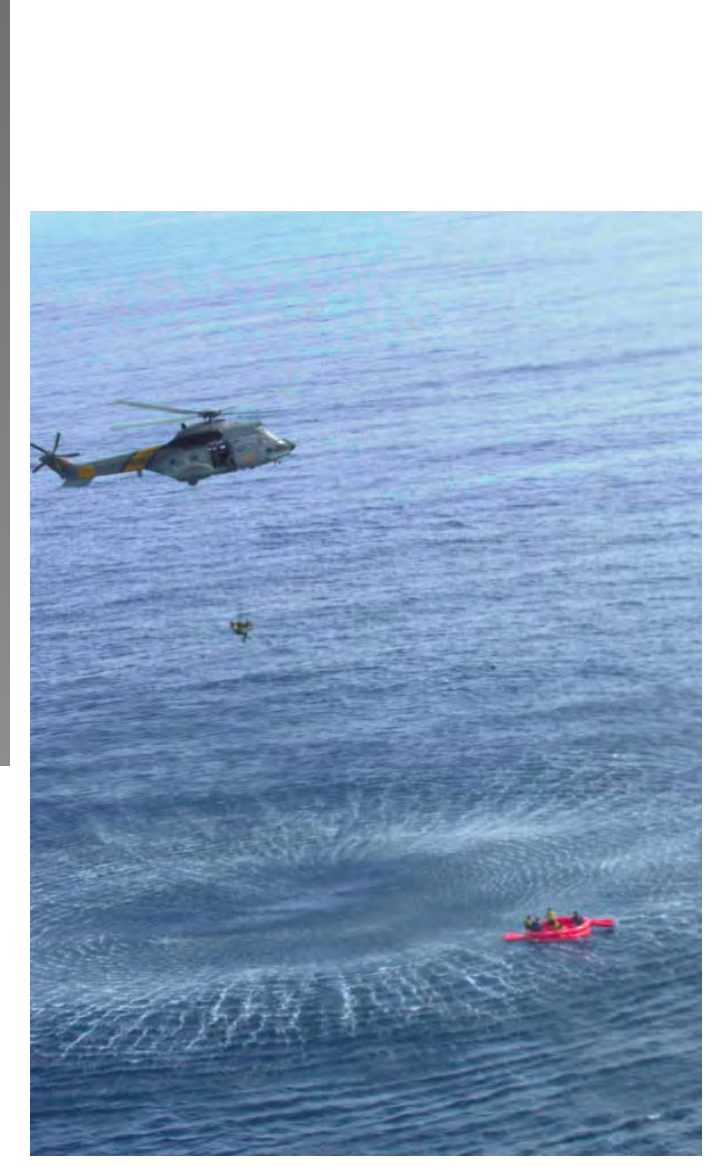

\section{需 Agenciacinaria




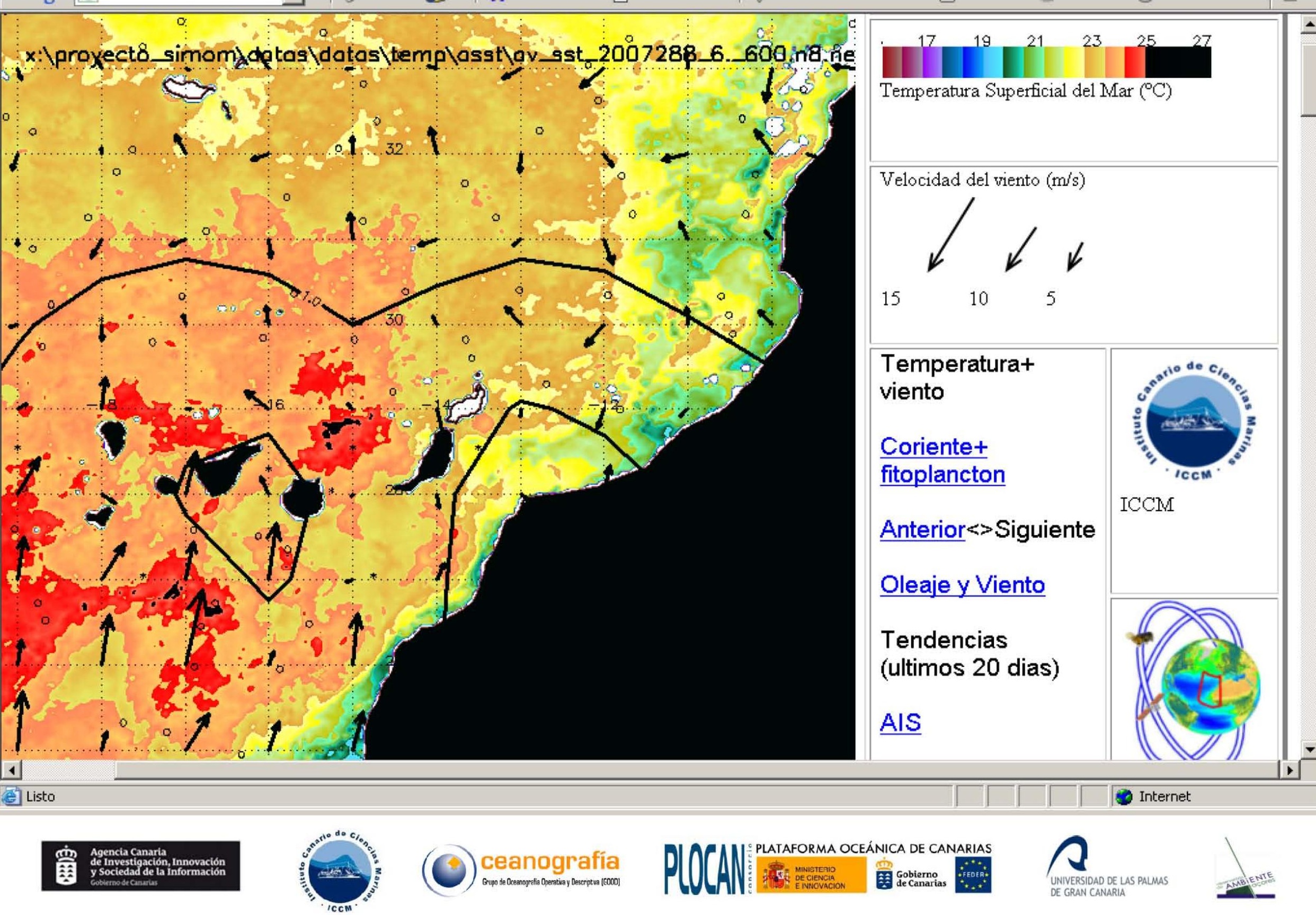




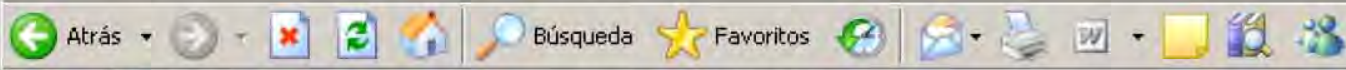

Dirección e http://Wwww-pre.iccm.rcanaria,es/boletines/webplayas/index.html

\section{Información de las Playas}

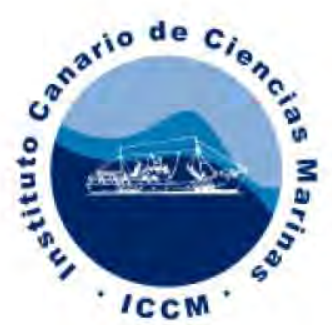

Seleccione la isla, para acceder a la informacion de sus playas, datos de temperatura del mar, velocidad y direccion del viento, determinado por zonas.

Una vez en los datos puedes recorrer isla por isla con los botones de avance y retroceso, o volver al menu principal.

Resolucion optima: $1024 \mathrm{x} 768$.

\begin{tabular}{|l|c|c|c|}
\hline & Temperatura & Viento & Dir. Viento \\
\hline $\begin{array}{l}\text { Zona Norte Icod de los vinos } \\
\text { (El Gomero, S. Marcos, St } \\
\text { Domingo,..) }\end{array}$ & $23.4^{\circ} \mathrm{C}$ & $\begin{array}{c}4.9 \mathrm{~m} / \mathrm{s} \\
(3 \mathrm{Bé})\end{array}$ & $\mathrm{NNE}$ \\
\hline $\begin{array}{l}\text { Zona Norte (Puerto de la } \\
\text { Cruz, Tejina, ..) }\end{array}$ & $25.3^{\circ} \mathrm{C}$ & $\begin{array}{c}4 \mathrm{~m} / \mathrm{s} \\
(3 \mathrm{Bé})\end{array}$ & $\mathrm{N}$ \\
\hline $\begin{array}{l}\text { Noreste (Las Teresitas, La } \\
\text { Hornilla, El Puertillo, ..) }\end{array}$ & $25.3^{\circ} \mathrm{C}$ & $\begin{array}{c}5.7 \mathrm{~m} / \mathrm{s} \\
(4 \mathrm{Bé})\end{array}$ & $\mathrm{NNE}$ \\
\hline $\begin{array}{l}\text { Zona Sureste (El Medano, } \\
\text { Poris, ...) }\end{array}$ & $25.4^{\circ} \mathrm{C}$ & $\begin{array}{c}4.9 \mathrm{~m} / \mathrm{s} \\
(3 \mathrm{Bé})\end{array}$ & $\mathrm{NNE}$ \\
\hline $\begin{array}{l}\text { Zona Suroeste (Los } \\
\text { Cristianos, Las Américas }\end{array}$ & $25.4^{\circ} \mathrm{C}$ & $\begin{array}{c}4.9 \mathrm{~m} / \mathrm{s} \\
(3 \mathrm{Bé})\end{array}$ & $\mathrm{NNE}$ \\
Fañabe, S. Juan, ...) & & & \\
\hline
\end{tabular}

« Anterior $\ll$ Fecha: $16 / 10 / 2007 \gg$ Siguiente $\gg>$

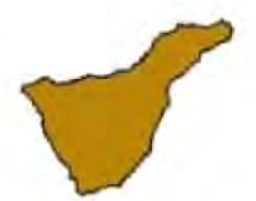

Tenerife

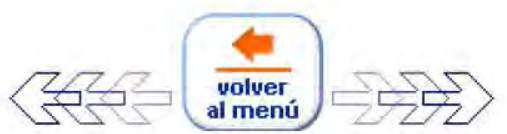

Instituto

Canario

de Ciencias

Marinas

Situacion Sinoptica sobre el estado de la mar

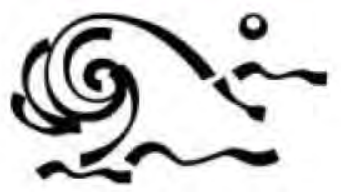


The Red ACOMAR Canarias Network A Real-Time Moored Buoy Network for Coastal Monitoring in

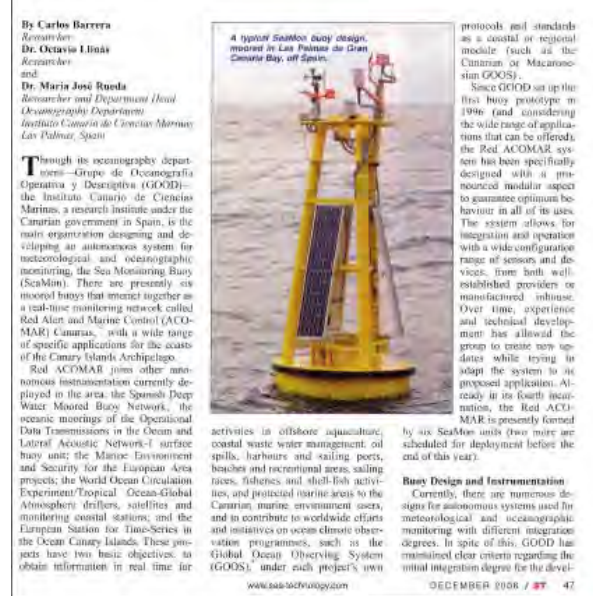

SeaTechnology

December 2006

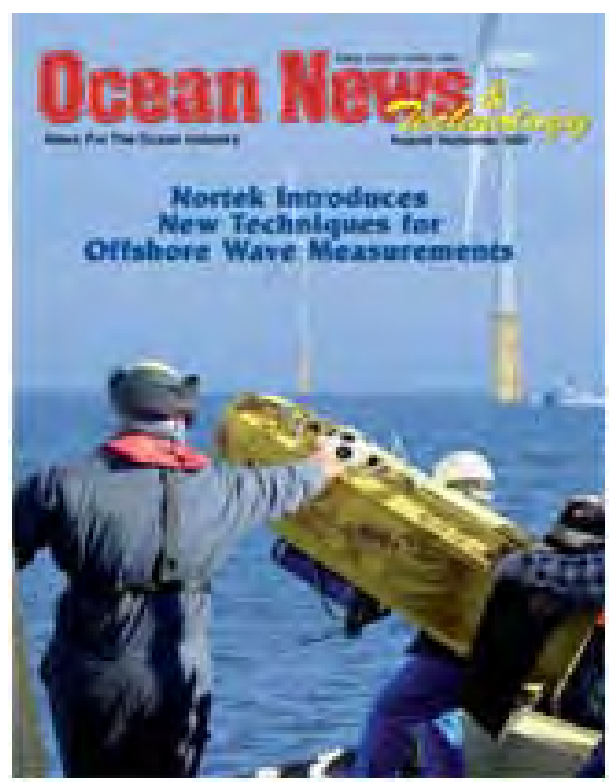

Ocean News \& Technology

November 2007
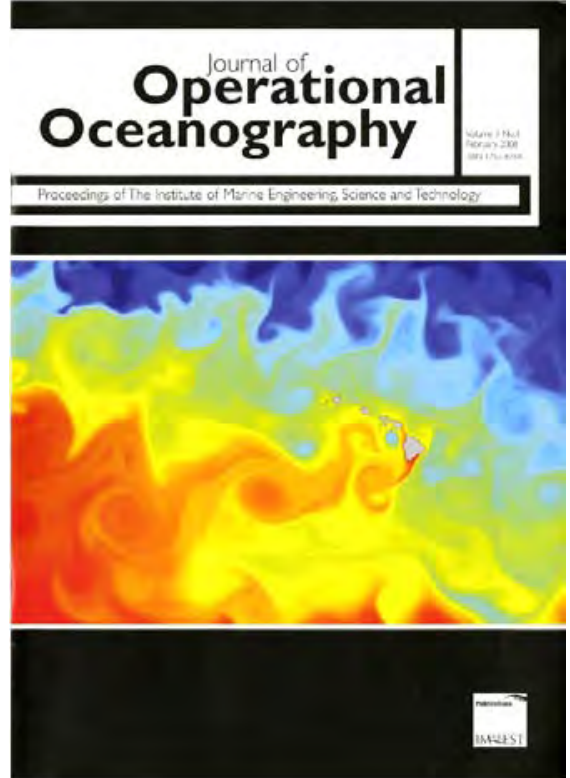

JOO

March 2008

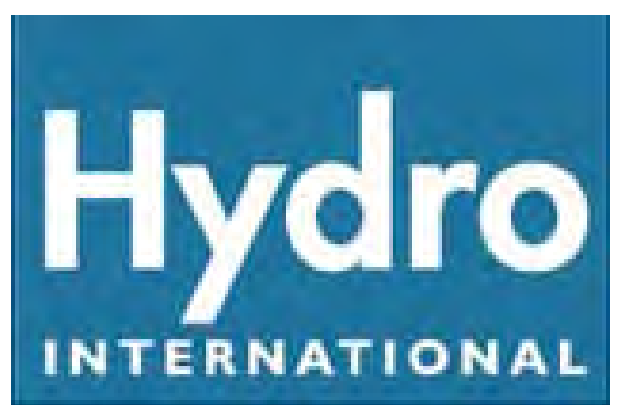

$104 \mid \begin{array}{lll}0 \\ 0\end{array}$
Hydro

February 2009 
The ACOMAR Network should be understud as a regional proposal to promote socio-economical approaches in the maritime sector through OPERATIONAL OCEANOGRAPHY ACTIVITIES and their DERIVED PRODUCTS. 


\section{AMASS}

Autonornous Maritime Surveillance System

The aMuss gropect in led by Cwel Zein Cpireatia, in collatoration with ae felisting srgarisutions:

unded Fanat of thin

Craste Conveting to

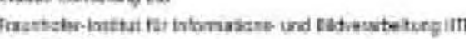
Fuppoctakck.

ief pod aro

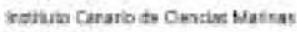

a viving

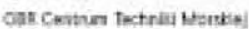

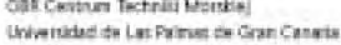

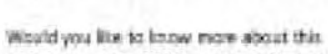

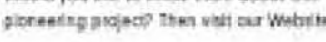

www.amees-projeot.eu

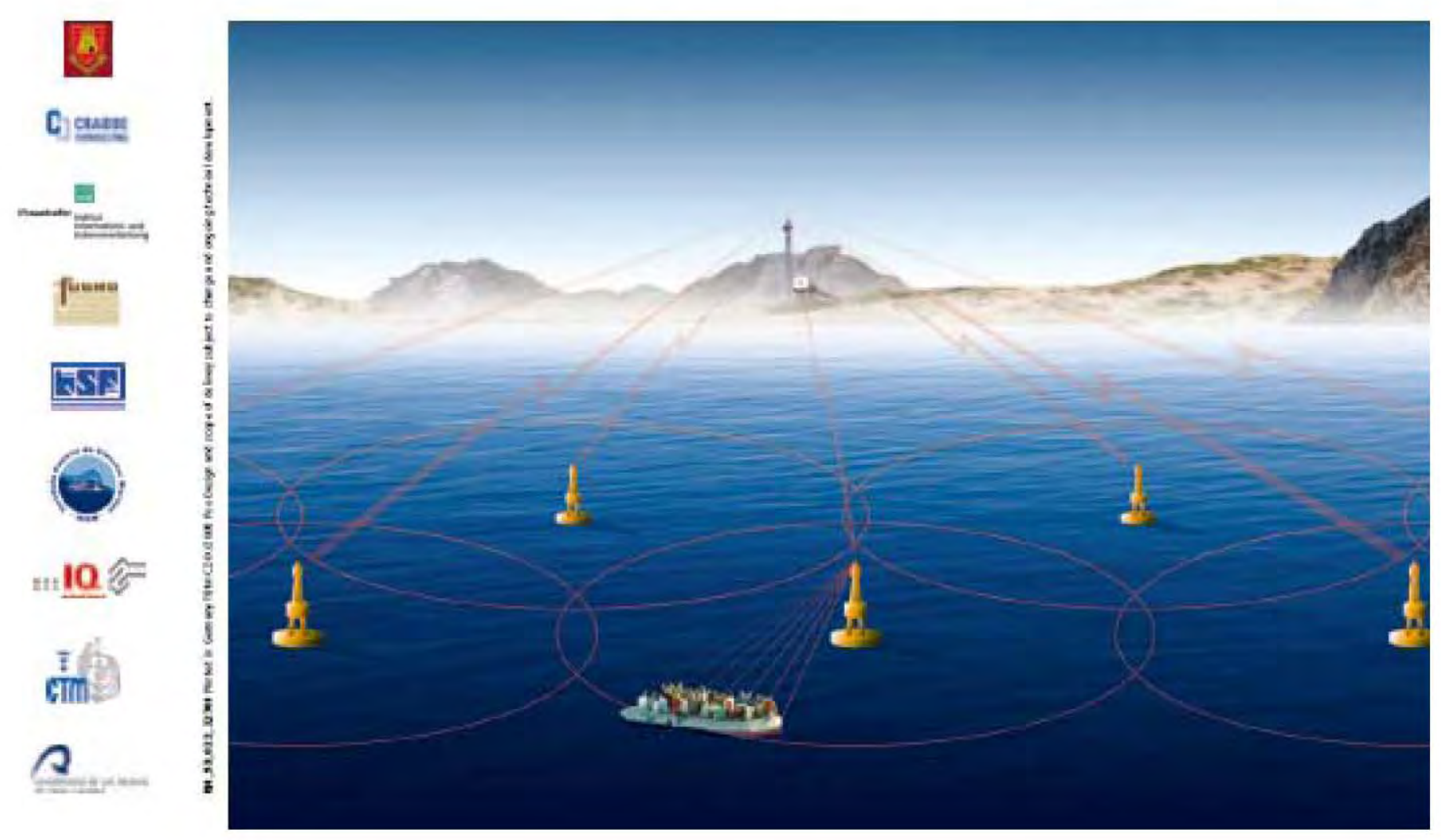




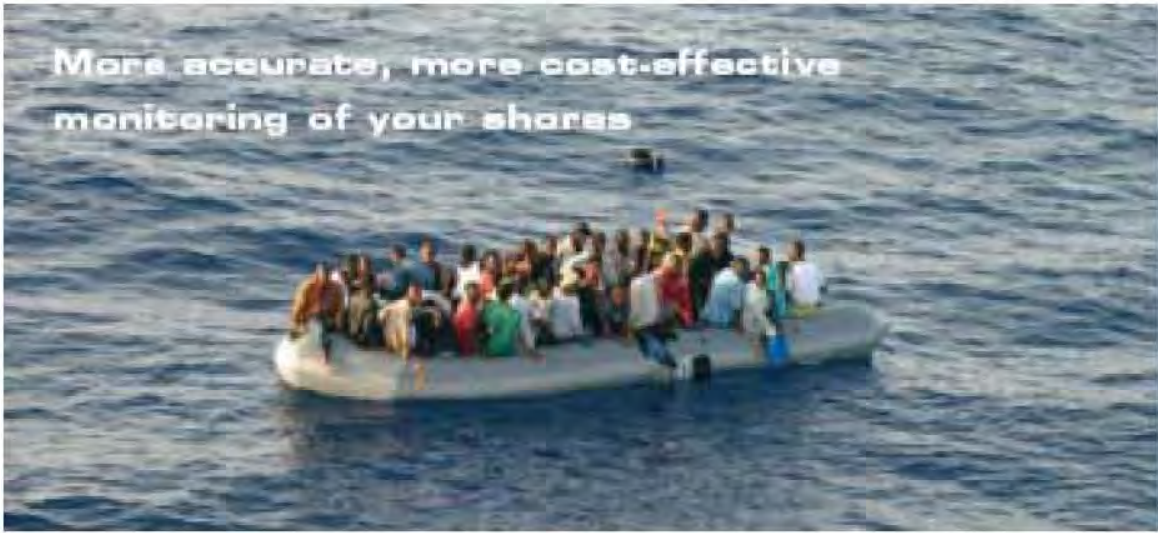

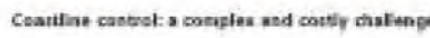

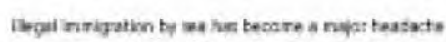

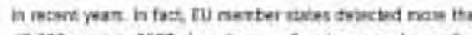

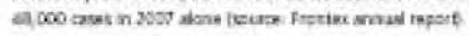

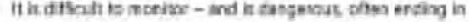

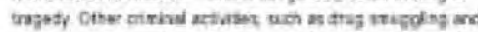

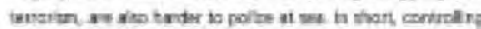

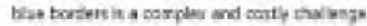

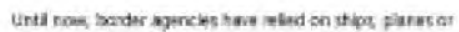

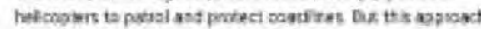

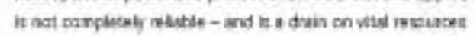

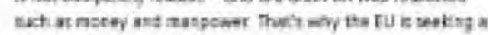

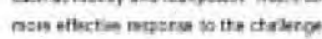

Cuespe usites in prontering groped

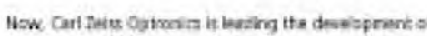

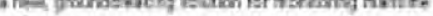

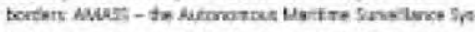

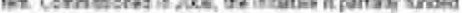

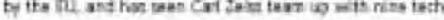

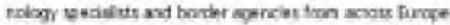

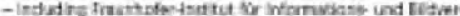

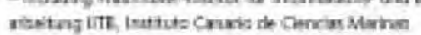
nit te Monsed laves at Mra

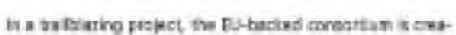

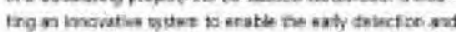

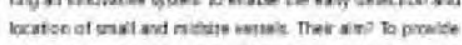

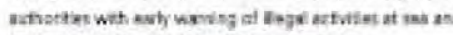

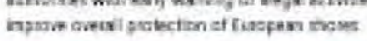

Banafite at a glance.

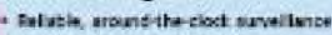

mproved trusions morkenas

- Hovr cant-elleime

Funcrions in al wastive esnaticer

- Intiar une of taman rassuca.

+ Gever aniety for All encen--.et

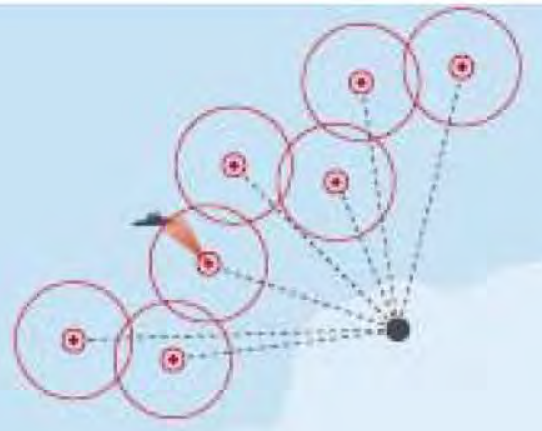

The nots and belte: ham it noche

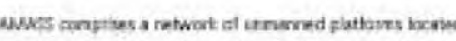

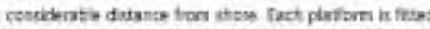

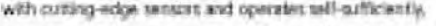

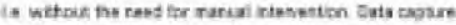

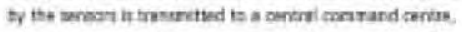

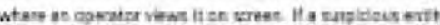

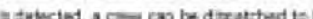
stim taier.
Anases on gaved

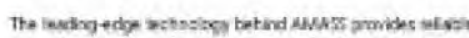

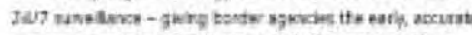

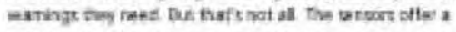

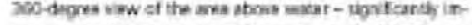

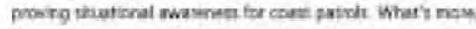

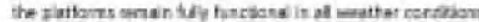

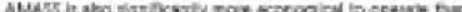

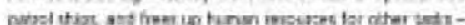
mol

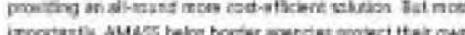

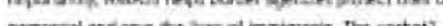

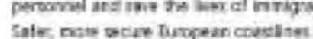
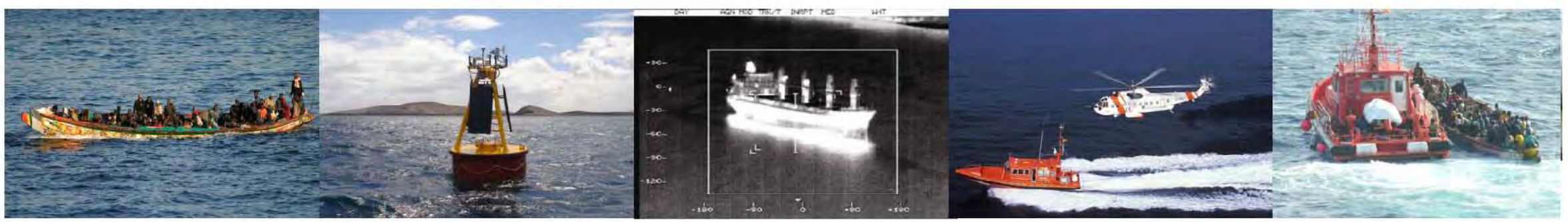

(i) Agencia Canaria 


\section{WELCOME}

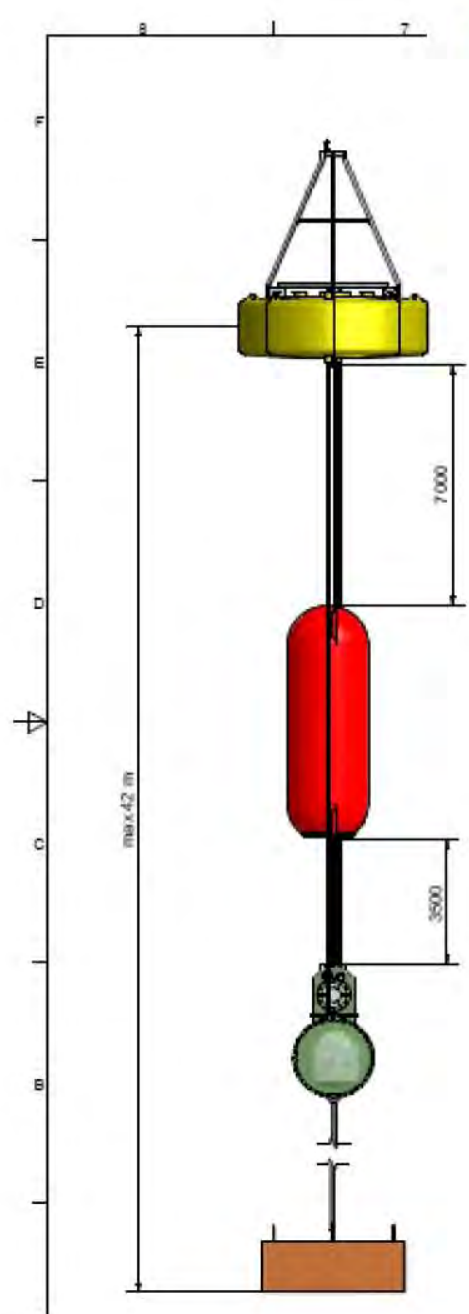

Wave Energy Lift COnverter Multiple España
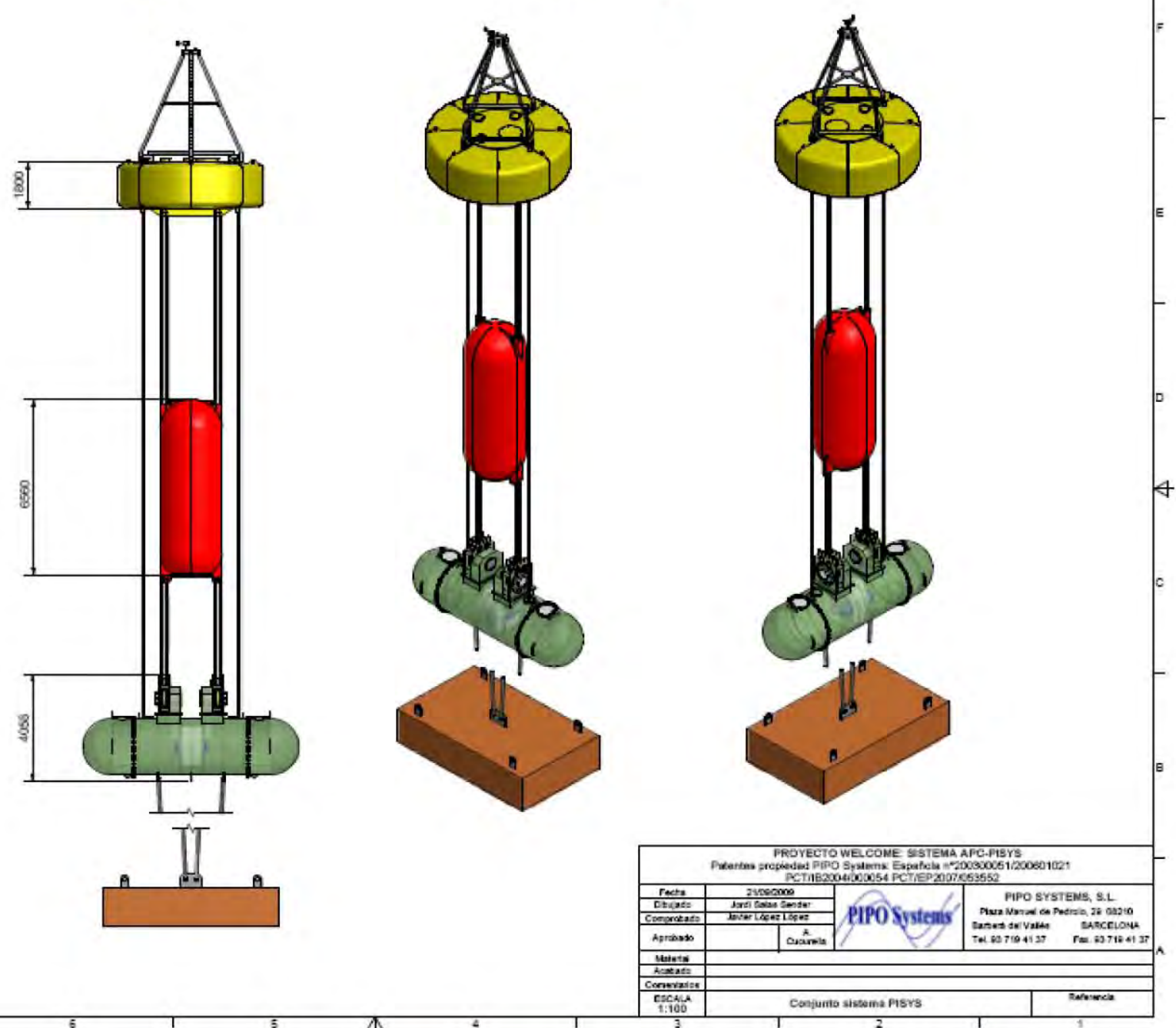

1 PLATAFORMA OCEÁNICA DE CANARIAS

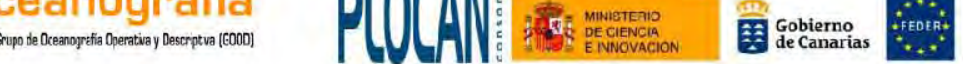




\section{WELCOME}

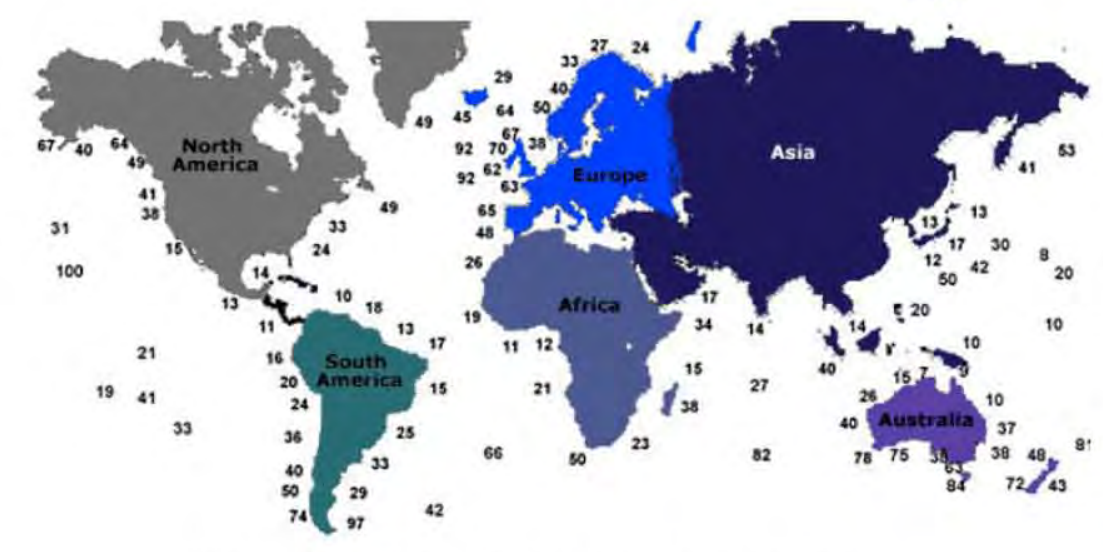

\section{Wave Energy Lift COnverter Multiple España}

Mapa mundial mostrando la energia media de olas en $\mathrm{KW} /$ metro de frente de ola

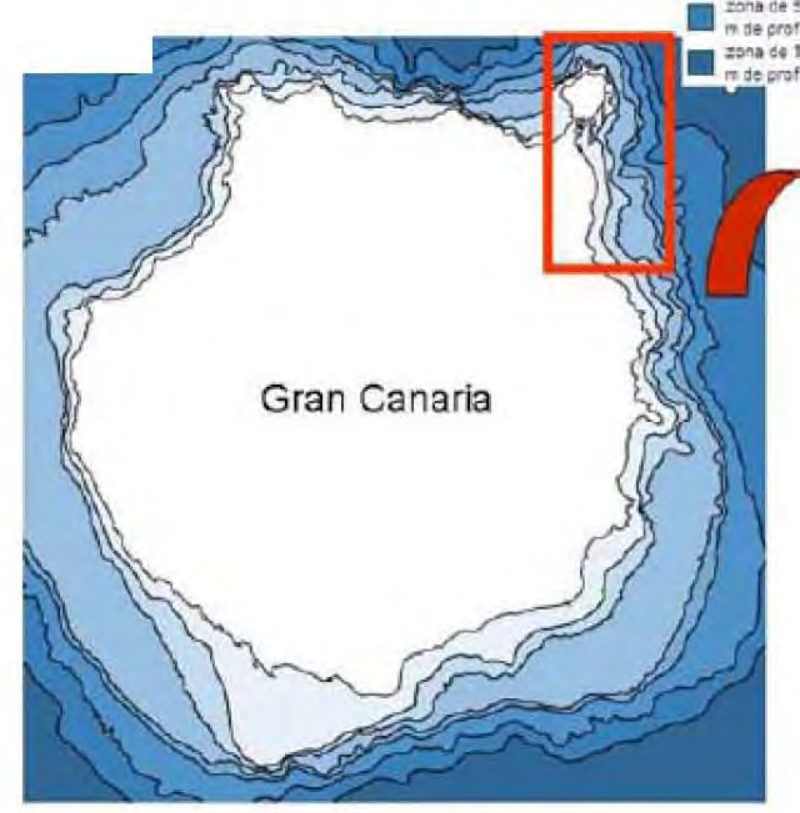

Puerto de Las Palmas.

Ensamblaje y test inicial

- Punto de fondeo. 

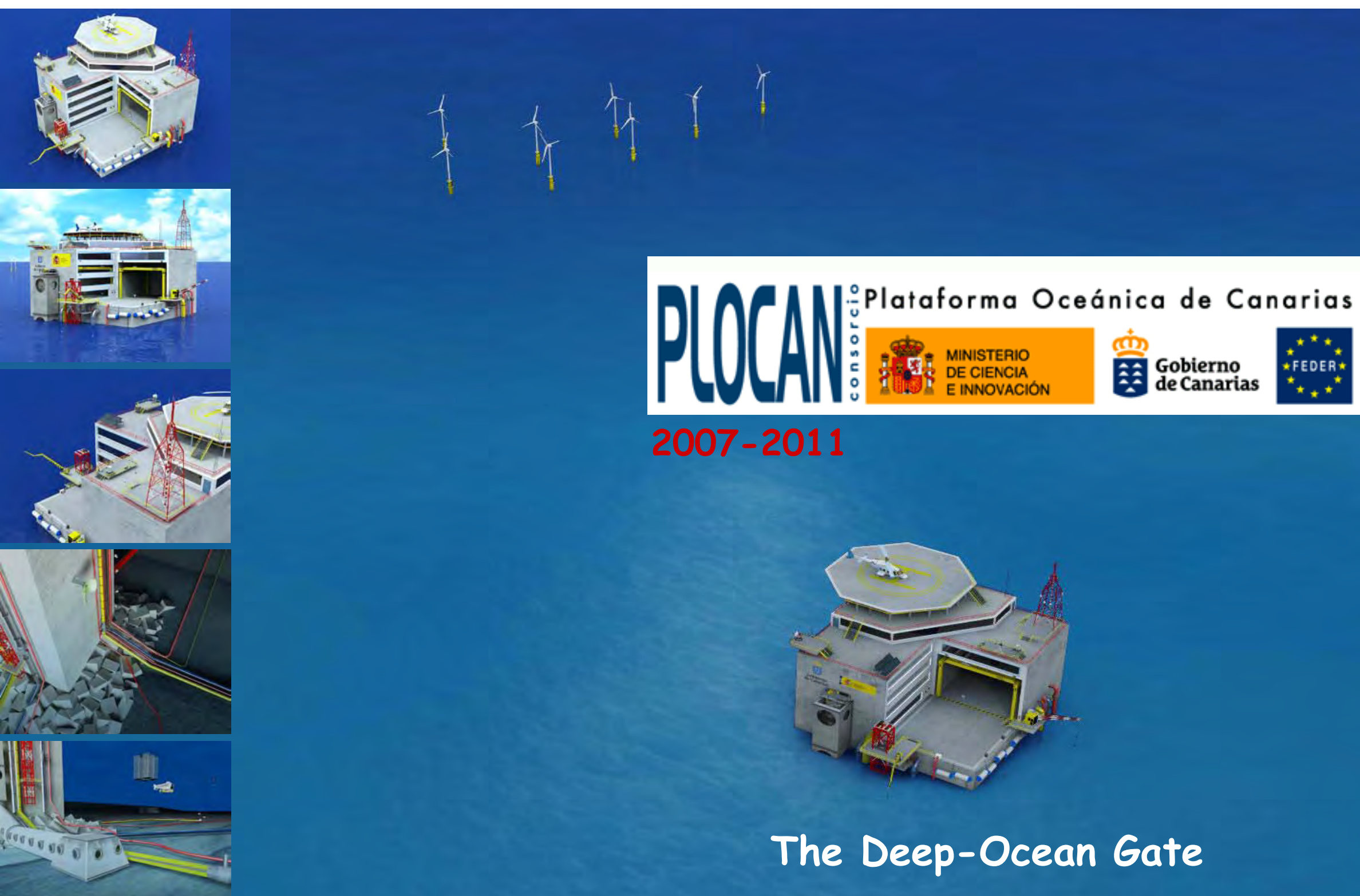

2007-2011

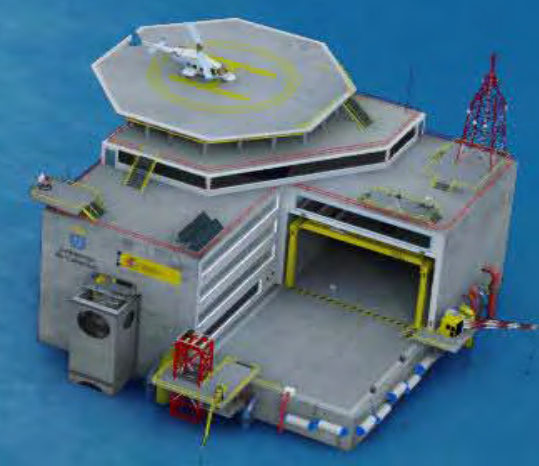

The Deep-Ocean Gate 


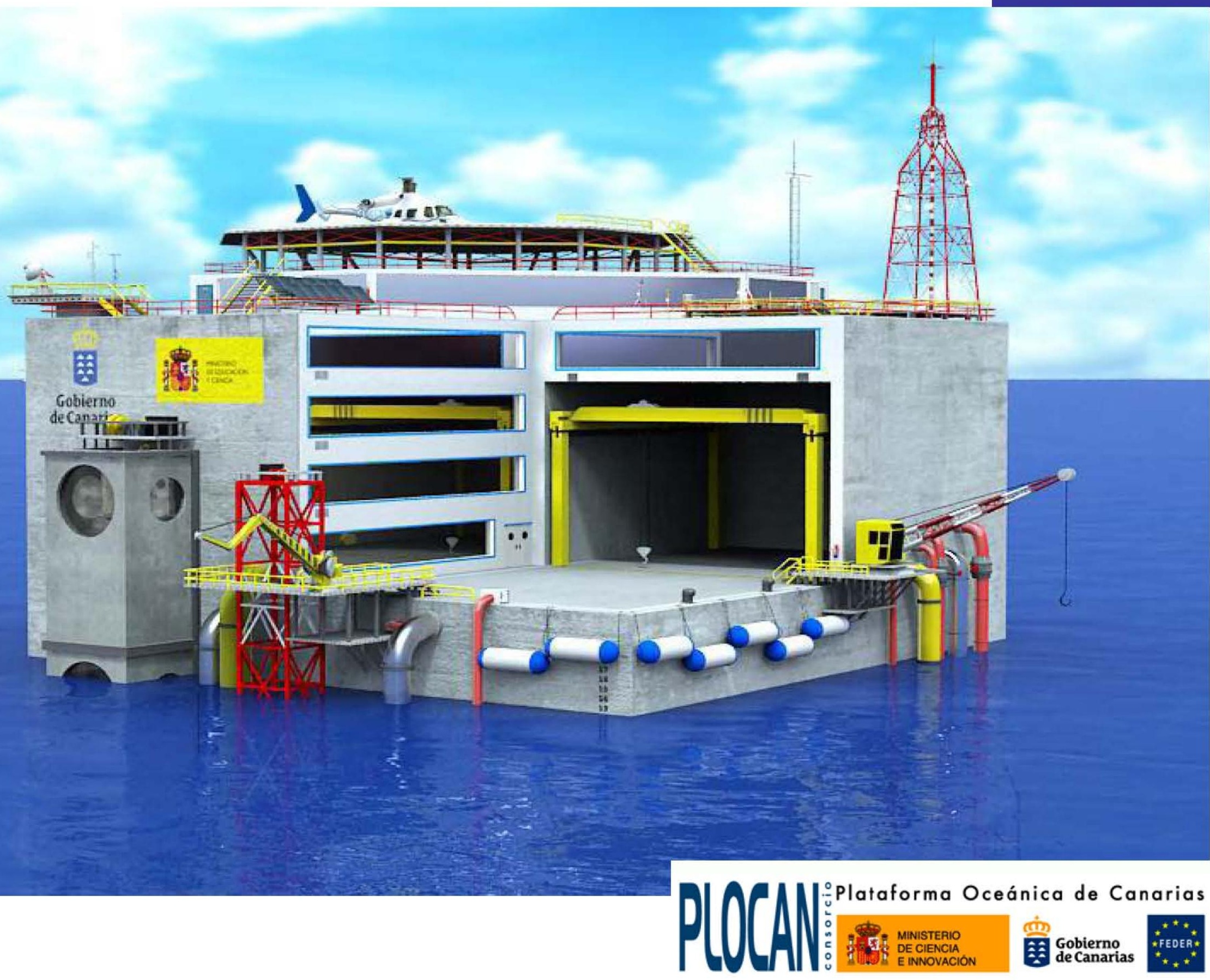




$$
\text { 千补1 }
$$

- OBSERVATORY

- BASE FOR UNDERWATER VEHICLES AND INSTRUMENTS

- TECHNOLOGICAL TEST BED

- SOCIO-ECONOMIC INNOVATION PLATFORM

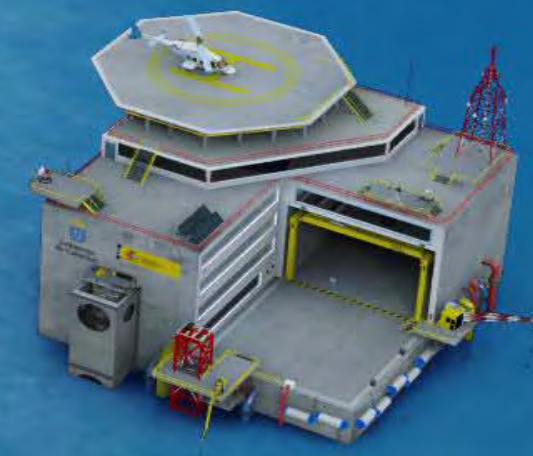




\section{Thank you for listening}

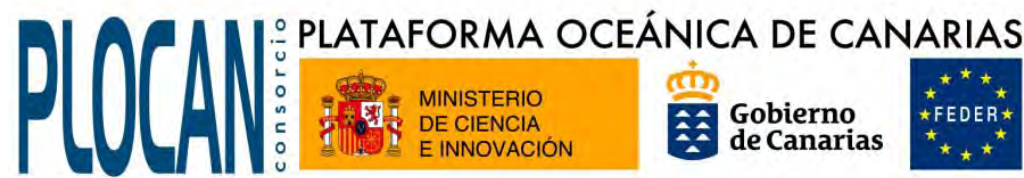
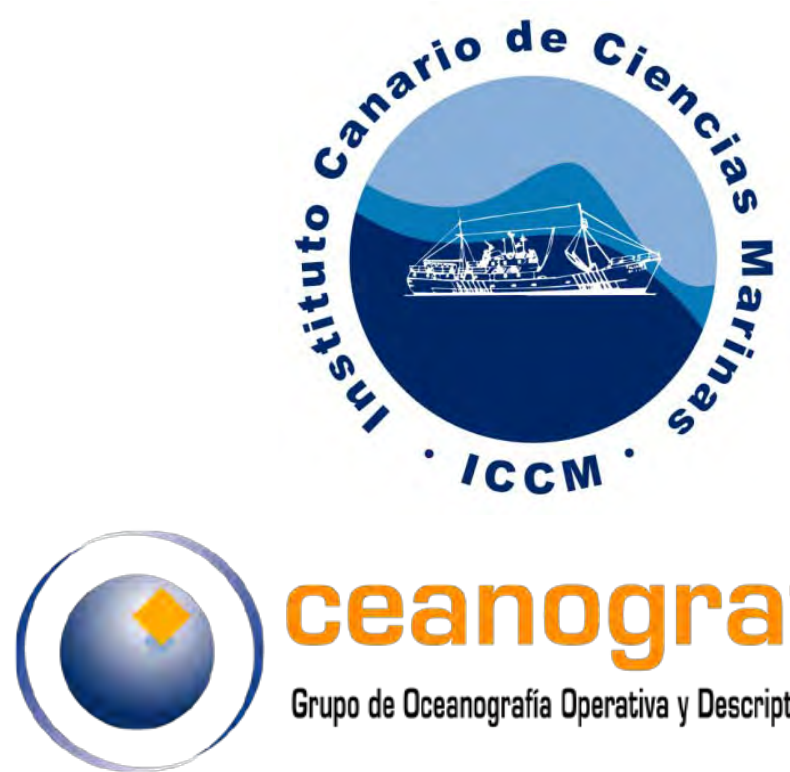

\section{ceanografía}

Grupo de Oceanografia Operativa y Descriptiva (GOOD)

...Any questions? 